\title{
Investor Attention, Visual Price Pattern, and Momentum Investing
}

\author{
Li-Wen Chen * \\ Department of Finance, National Chung Cheng University \\ 168 University Road, Minhsiung Township, Chiayi County 62102, Taiwan, \\ Tel: +886-5-2720411 ext. 24213; Fax: +886-5-2720818; Email: lwchen@ccu.edu.tw
}

\section{Hsin-Yi Yu}

Department of Finance, National University of Kaohsiung

700, Kaohsiung University Rd., Nanzih District 81148, Kaohsiung, Taiwan

Tel: +886-7-5919709; Fax: +886-7-5919329; Email: hyyu@nuk.edu.tw

\footnotetext{
* Corresponding author. This paper was previously titled "Momentum-Reversal Strategy". The research data were collected during the study at the University of Edinburgh. This paper has benefited from discussions with and comments from John K. C. Wei, Jason Wei, Akindynos-Nikolaos Baltas, and the participants at the 20th Conference on the Theories and Practices on Securities and Financial Markets. We also acknowledge financial support from the National Science Council.
} 


\title{
Investor Attention, Visual Price Pattern, and Momentum Investing
}

\begin{abstract}
Since investor attention is limited, stocks that attract attention are more likely to be chosen, while stocks that do not attract attention are often ignored. Given that a visual mode of analysis is more conductive to human cognition than algebraic numbers, we propose that the visual pattern of past prices is a salient signal that attracts investor attention, and thereby boosts returns. The stocks in the winner and loser groups are further classified based on their visual patterns of past prices. We construct a long-short portfolio including the stocks which are more likely to grab investor attention by their discernible visual patterns of past prices. Our long-short portfolio commands a compounded annual risk-adjusted return of $23.1 \%$, almost double the conventional momentum profit. The outperformance holds under various alternative specifications. Moreover, the sheer size of these profits poses a further, significant challenge to the asset pricing literature and the market efficiency hypothesis.
\end{abstract}

Keywords: Momentum; Technical Analysis; Limited Attention; Past Price JEL code: G11, G12, G14 


\section{Introduction}

Traditional asset-pricing models are typically based on the assumption that new information diffuses efficiently so the market can provide the best possible estimate of all asset values. However, attention requires effort. In reality, such diffusion and estimation requires investors' close attention to processing information and to incorporating this knowledge into their decisions. If the amount of information available is vast, the investors must be selective in the information they process. As Kahneman argues, attention is a scarce cognitive resource (Kahneman, 1973). A large body of psychological research shows that there is a limit to the cognitive-processing capacity of the human brain. Recently, more and more studies suggest that investor attention could play an important role in determining asset prices, for example Barber and Odean (2008), Hou, Peng, and Xiong (2009), Hirshleifer, Lim, and Teoh (2012) and Li and Yu (2012). This paper studies the effects of investor attention on momentum investing.

Various models and theories have been put forward to explain the co-existence of intermediate-term momentum and long-term reversal. The related literature is voluminous. Intermediate-term (3-12 months) momentum is documented by Jegadeesh and Titman (1993 and 2001), while short-term (weekly) and long-term (3-5 years) reversals are 
documented by Lehmann (1990) and Jegadeesh (1990), and DeBondt and Thaler (1985) respectively. Researchers have explored explanations for these phenomena along the behavioral avenue, for example Chan, Jegadeesh and Lakonishok (1996), Barberis, Shleifer, and Vishny (1998), Daniel, Hirshleifer, and Subrahmanyam (1998); Hong and Stein (1999), and Hong, Lim, and Stein (2000). The linkage between momentum and various firm characteristics is also explored (e.g. Avramov, Chordia, Jostova, and Philipov (2007) and Wei and Yang (2012)). Recently, an intriguing study by George and Hwang (2004) suggests that traders might use the 52-week high as an anchor when assessing the increment in stock value implied by new information. They argue that a stock whose price is at or near its 52-week high is one for which good news has recently arrived, and that this may be precisely the time when traders' underreaction to good news is at its peak. Hence, nearness to the 52-week high is positively associated with expected returns in the cross section.

We argue that investor attention could play a dual role in determining the momentum profit. On one hand, limited attention can cause investors to ignore important information, which leads to stock price underreaction, as George and Hwang (2004) suggest. On the other hand, investor attention can also interact with behavioral biases to generate overreaction. As Hou, Peng, and Xiong (2009) argue, attention is a necessary 
condition for overreaction, since investors can only overreact to information when they pay attention to a stock. Since visual information more easily catches the eye than raw numbers, we expect that some specific visual patterns of past prices will grab investor attention, induce overreaction, and finally boost future returns.

Analyzing the visual patterns of past prices sounds like technical analysis. Technical analysis has been criticized by academic finance from the very start. One reason for this is the subjective and impenetrable jargon used by technical analysts ${ }^{1}$. The major difference between academic finance and technical analysis is that the latter is "primarily visual, whereas quantitative finance is primarily algebraic and numerical" (Lo, Mamaysky, and Wang, 2000, [1706]). Unlike technical analysis, which depends on subjective judgment, this paper uses an objective regression to describe the visual pattern of a stock's past prices and pick stocks which are more likely to grab investor attention by their conspicuous patterns.

Our sample covers all common stocks listed in NYSE, AMEX, and Nasdaq from the CRSP monthly file. The sample period is from January 1962 to December 2011. Paralleling the procedure in Jegadeesh and Titman (1993, hereafter JT), we first sort

\footnotetext{
${ }^{1}$ Although technical analysis is known as "voodoo finance", Lo, Mamaysky, and Wang (2000) employ a systematic and automatic approach to technical pattern recognition and find that several technical indicators do provide incremental information and may have some practical value. Lo and MacKinlay $(1988,2001)$ have also shown that past prices may be used to forecast future returns to some degree, a fact that all technical analysts take for granted.
} 
stocks into quintiles based on past $J$ months' returns to identify winners and losers. From among these winners and losers, we conjecture that investors will flock to those with eye-catching visual charting of past prices. To identify the visual pattern of past prices, we secondly regress the past daily prices in past $J$ months on time dummy and the square of time dummy for each stock to investigate the concavity/convexity of its past returns, and further sort stocks in the winner and loser groups according to the coefficients of the square of time dummy. Intuitively, the convex-shaped past prices in the winner group more easily attract attention than concave-shaped past prices, because convex-shaped past prices reveal that the price increases at an accelerative speed. Conversely, concave-shaped past prices imply that the rise in price slows down. Following this vein, the concave-shaped past prices in the loser group are also more attractive for those who short-sell than convex-shaped past prices, because the visual impression is stronger for stocks whose prices decrease in an accelerated way.

In order to explore the practical implications of the visual pattern of past prices, we design nine trading strategies and compare the returns and the risk-adjusted returns of different trading strategies. Each strategy buys and short-sells stocks with different levels of convexity/concavity. For the case of a 6-month holding based on the past 12-month returns, the plain momentum strategy (buy winners and sell losers) produce a profit of 
83.22 basis points per month. However, a strategy which buys stocks whose past prices are extremely convex-shaped in the winner group and sells stocks whose past prices are extremely concave-shaped in the loser group can generate 132.46 basis points per month, approximately $17.11 \%$ annually. Meanwhile, the converse trading strategy, which buys and sells stocks which are least likely to trigger investor overreaction (i.e. buy stocks whose past returns are concave-shaped and sell stocks whose past returns are convex-shaped), produces the lowest return -46.80 basis points per month. The findings are robust to sample division into subperiods and exchanges, replacing the daily closing prices by the midpoints of bid and ask quotes, removing January returns, and various holding/ranking periods. We also find the existence of reversals for a holding period of 24 months. The reversals confirm the investor attention hypothesis.

Our findings are important not only for researchers in asset pricing but also for practitioners interested in asset management and the performance evaluation of portfolios. For practitioners, we propose an extremely promising trading strategy that should be of interest to a wide range of investors, especially hedge funds. Our new strategy is feasible and easy to implement given the sheer size of the new portfolio. For researchers, we provide empirical evidence for the implications of a well-established psychological constraint - limited investor attention. We argue that limited attention offers a 
parsimonious explanation for the momentum profit because investors will flock to stocks which grab their attention and thereby generate return autocorrelation. Therefore, we can distill new information from the visual patterns of past returns and construct portfolios with higher risk-adjusted returns correspondingly.

The remainder of this paper is organized as follows. Section 2 describes the motivation and hypotheses. Section 3 outlines the data and proposes new trading strategies. In Section 4 we report the empirical findings. Section 5 presents some auxiliary tests. Section 6 concludes the paper.

\section{Motivation and Hypothesis}

The phenomena of momentum and reversal, a fact that all technical analysts take for granted, have been discussed in many studies. Short-term (weekly) and long-term (3-5 years) reversals are documented by Lehmann (1990) and Jegadeesh (1990), and DeBondt and Thaler (1985) respectively, while intermediate-term (3-12 months) momentum is documented by Jegadeesh and Titman (1993 and 2001). Cross-sectional return predictability appears to be prevalent in different markets (Rouwenhorst, 1998; Doukas and McKnight, 2005) and different asset classes (Asness, Moskowitz, and Pedersen, 
2009). It also exists between and within industries (Moskowitz and Grinblatt, 1999; and Hameed, Huang, and Mian, 2010).

Various models and theories have been put forward to explain the co-existence of intermediate-term momentum and long-term reversal. Some explanations are consistent with the efficient market hypothesis, for instance Berk, Green, and Naik (1999), Conrad and Kaul (1998), and Chordia and Shivakumar (2002), but some other explanations attribute momentum and reversals to systematic violations of rational behavior by investors. In Barberis, Shleifer, and Vishny (1998) and Hong and Stein (1999), fundamental investors tend to underreact to new information, and momentum traders arbitrage away the profit fundamental investors leave behind, resulting in intermediate-term momentum. However, these momentum traders subsequently overcorrect and push the price away from fundamentals. In Daniel, Hirshleifer, and Subrahmanyam (1998), momentum is a consequence of investors' tendency to overreact to private information due to self-attribution and overconfidence, and reversals occur when such mispricing is corrected.

Attention is a necessary condition for overreaction, since investors can only overreact to information when they pay attention to a stock after becoming aware of the information. Attention is the cognitive process of selectively concentrating on one aspect 
of the environment while ignoring other things (Anderson, 2004). According to Paivio's (1986, 1971) dual-coding theory, picture stimuli have an advantage over word stimuli because they are dually encoded. Pictures generate a verbal and image code, whereas word stimuli only generate a verbal code. In other words, pictures are likely to generate a verbal label, whereas words are not likely to generate image labels. Following the dual-coding theory, the picture superiority effect infers that concepts that are learned by viewing pictures are more easily and frequently recalled than concepts that are learned by viewing their written words from counterparts. This picture superiority effect has implications for salience in attribution theory, the availability heuristic, as well as advertising (Whitehouse, Maybery, and Durkin, 2006)².

The potential implication of the picture superiority effect in the stock market should be technical analysis, also known as “charting” (Lo, Mamaysky, and Wang, 2000). An important difference between technical analysis and quantitative finance is that technical analysis is primarily visual and geometric, whereas quantitative finance is primarily algebraic and numerical. The main task of technical analysis is to predict how investors as a whole will react ex post when the specific charts are observed ex ante. However, the

\footnotetext{
${ }^{2}$ For more information about the picture superiority effect, please refer to Shepard (1967), McBride and Dosher (2002), Defetyer, Russo, and McPartlin (2009), Ally, Gold, and Budson (2009), Curran and Doyle (2011).
} 
presence of specific geometric shapes in historical price charts often depends on personal judgment. Moreover, technical analysis seldom uses any fundamental information but focuses on market information, such as prices and volume.

Previous studies argue that momentum can be ascribed to psychological biases. If the visual mode of analysis is more conductive to human cognition and more easily induces psychological biases, we can conjecture that recognizing the pattern of past data can provide incremental value to the momentum strategy. Conversely, if momentum is not induced by psychological biases, analyzing the visual patterns of past data should not enhance profitability.

Like the 52-week high and low documented in George and Hwang (2004), the chart of past prices is the most common information investors will notice and that broker software and websites will provide. We therefore focus on the visual pattern of past prices to observe whether buying or selling stocks with specific patterns of past prices can add value to the momentum strategy. Some may argue that analyzing the patterns of past prices is just one kind of technical analysis. In fact, technical analysis assumes that all investors, whether rational or irrational, will trade in the same direction without hesitation when specific charts are observed, let alone the subjective pattern recognition and 
impenetrable jargon in technical analysis ${ }^{3}$. However, this study starts from the assumption that some investors are not entirely rational but psychologically biased. So they will be attracted by specific visual modes of historical prices.

\section{Data and Trading Strategies}

3.1. Data

All common stocks (share codes 10 and 11) listed in the NYSE, AMEX, and Nasdaq are included in our sample. The data are collected from CRSP daily and monthly files. The monthly data is used to calculate portfolio returns, while daily data is used in the regression and the calculation of firm characteristics at the later stages. The sample period is from January 1962 to December 2011. We filter out the stocks whose prices are below 5 dollars on the portfolio formation date ${ }^{4}$. We also retrieve accounting data from COMPUSTAT to calculate book-to-market ratios and other variables for our regression

\footnotetext{
3 The pioneer work of Lo, Mamaysky, and Wang (2000) proposes a systematic and automatic approach to technical pattern recognition using nonparametric kernel regression. They find that over the 31-year sample period, several technical indicators can provide incremental information and may have some practical value.

${ }^{4}$ We also use all common stocks listed in the NYSE, AMEX, and Nasdaq without any data filter to do the analysis. All empirical results remain unchanged.
} 
analyses. Throughout our analysis, we employ the corrections suggested in Shumway (1997) for the de-listing bias; however, these adjustments have no effect on our results.

\subsection{Visual Pattern of Past Returns and the Trading Strategies}

We identify the visual pattern of past prices using an objective method. We first sort stocks into quintiles based on past returns. The stocks in each quintile are further sorted into quintiles based on various visual shapes of past returns. Concretely, we first parallel the methodology of JT (1993) to sort stocks. At the beginning of each month $t$, we sort stocks based on the returns of the previous $J$ months into quintiles. To avoid the microstructure issues identified by previous researchers (e.g. Jegadeesh and Titman, 1993; and Chan, Jegadeesh, and Lakonishok, 1996), we skip one full month between the formation period and the holding period. For illustration, when $J$ is equal to 12 , at month $t$ we sort stocks based on their returns from month $t-13$ to month $t-2$.

Secondly, we run the following regression for each stock by using daily data to increase the power of our tests.

$$
P_{i, t}=\alpha+\beta t+t^{2}
$$

where $P_{i, t}$ is the daily price of stock $i$ at time $t . t$ is an arithmetic sequence, which is 
equal to $1,2,3 \ldots$ or $n$ for the indication of the past $n, \ldots, 3,2$, or 1 day respectively. At the beginning of each month, the daily returns in the previous $J$ months (lagged one month) are used to run the regression (1) and determine the sign of the coefficients. We further sort stocks in each return group to quintiles based on the value of $\gamma$. Overall, we have $5 \times 5$ portfolios.

If the coefficient of $\gamma$ is positive (negative), the return of the stock is a convex (concave) function of time. For a winner stock, a convex-shaped pattern of past prices shows that they increase at an accelerative speed, whereas a concave-shaped pattern of past prices illustrates that the increasing speed of price rises gradually slows down. Intuitively, the convex-shaped pattern should grab more investor attention than the concave-shaped pattern. Similarly, for a loser stock, a concave-shaped pattern of past prices shows that past prices decrease at an accelerative speed, while a convex-shaped pattern of past prices suggests that the speed of the price decrease gradually slows down. The acceleration of price decline in the former case is more attention-grabbing than the latter case. In summary, a winner stock with a convex-shaped chart of past prices and a loser stock with a concave-shaped chart of past prices are attractive to investors who want to buy or short respectively. We expect that higher returns can be extracted from the two kinds of stocks if momentum is attributed to psychological biases. 
To examine whether our conjecture is true, several trading strategies are constructed, as follows.

Strategy 1: Buy winners and sell losers.

Strategy 2: Buy winners and sell convex-shaped losers (i.e. stocks whose $\gamma$ are in the top $20 \%$ of the loser group).

Strategy 3: Buy winners and sell concave-shaped losers (i.e. stocks whose $\gamma$ are in the bottom $20 \%$ of the loser group).

Strategy 4: Buy concave-shaped winners (i.e. stocks whose $\gamma$ are in the bottom $20 \%$ of the winner group) and sell losers.

Strategy 5: Buy convex-shaped winners (i.e. stocks whose $\gamma$ are in the top $20 \%$ of the winner group) and sell losers.

Strategy 6: Buy convex-shaped winners and sell concave-shaped losers.

Strategy 7: Buy concave-shaped winners and sell convex-shaped losers.

Strategy 8: Buy convex-shaped winners and sell convex-shaped losers.

Strategy 9: Buy concave-shaped winners and sell concave-shaped losers.

Following Jegadeesh and Titman (1993), we hold overlapping portfolios for all 
strategies. Specifically, the sorting and portfolio formation procedure is repeated each month, and the returns of the long-short portfolio are equally weighted averages of the monthly returns on the overlapping portfolios. Each zero-cost portfolio will be held for $K$ months. The $t$-values for the portfolio returns are corrected for serial correlations via the Newey-West adjustment.

The first strategy is the traditional momentum strategy documented in JT (1993). Given that the concave-shaped losers will grab the attention of investors who want to short these stocks, more short-selling will further drive down the prices and thereby cause lower returns. Similarly, investors will flock to the convex-shaped winners and boost the returns. Hence, we can make several conjectures.

First, the profit of Strategy 3 is higher than that of Strategies 1 and 2. In a similar vein, we also expect that the profit of Strategy 5 is higher than that of Strategies 1 and 4 . Strategy 7 should achieve the highest returns among the nine strategies. In contrast to Strategy 7, we expect that the return of Strategy 8 is the lowest of all the strategies. The Fama-French three-factor model is used to measure the risk-adjusted returns of the nine strategies. The factor data are collected from the website of Kenneth R. French.

\section{The Empirical Evidence from the New Strategies}




\subsection{The Profits of the New Strategies}

Before showing the profits of the nine trading strategies introduced above, we first discuss the returns of different combinations of $(J, K)$ under the dependent double partition. We first sort stocks based on their past $J$-month returns lagged one month, and then sort the stocks in each return group on the coefficient $\gamma$ in equation (1). Foremost, Table 1 demonstrates that we can still distinguish stocks by their convexity/concavity of past prices; otherwise, significant raw returns should not be observed. Panel A of Table 1 reports the raw returns of buying the stocks whose $\gamma$ are in the top 20\% and shorting the stocks whose $\gamma$ are in the bottom $20 \%$ for the winner stocks. We find that most of the raw returns of convex-shaped winners are significantly higher than concave-shaped winners. This finding implies that when the prices increase at an accelerative speed, investors' attention will be grabbed and stronger psychological biases will be induced.

Panel B reports the difference in raw returns between convex-shaped and concave-shaped for the loser stocks. Such outperformance is less significant in the loser group but can still be found in some $(J, K)$ combinations. The raw returns of concave-shaped losers are significantly lower than convex-shaped losers, which means 
that short-selling these concave-shaped losers can generate higher returns. This finding is also consistent with the argument that investor attention will be caught when prices decrease at an accelerative speed. This accelerative decreasing pattern sets off more short-selling and finally creates a further price decrease.

\section{[INSERT TABLE 1 HERE]}

To explore the practical implications of the visual pattern analysis, we examine the performance of the nine zero-investment trading strategies discussed in Section 3.2. Panel A of Table 2 presents the raw and risk-adjusted returns obtained from the Fama-French three-factor model for the nine trading strategies. For brevity, hereafter we focus our attention on the case $(J, K)=(12,6)$ across this paper. The main results remain quantitatively and qualitatively similar under other combinations ${ }^{5}$.

The monthly momentum profit (Strategy 1) is 83.22 basis points (all months included) and 105.89 basis points (January excluded). In addition to buying winners and shorting losers, in Strategy 6 we buy winner stocks whose past prices increase acceleratively (convex-shaped) and short loser stocks whose past prices decrease

\footnotetext{
${ }^{5}$ In fact, when the ranking period is longer (i.e. $J$ is larger), the raw and risk-adjusted returns are higher.
} 
acceleratively (concave-shaped), since the visual patterns of these stocks are more likely to grab investor attention. Compared to the benchmark, three features stand out. First and foremost, Strategy 6 outperforms all the other strategies. Its monthly raw return is 132.46 basis points, approximately $17.11 \%$ annually. The Sharpe ratio is also higher than the momentum strategy. Secondly, the performance of Strategy 7 is 46.8 basis points per month, achieving the least profit among all strategies. In Strategy 7 we conversely buy and short stocks which are less likely to attract investor attention in the winner and loser groups. Both the outperformance of Strategy 6 and the underperformance of Strategy 7 correspond to our expectation.

Thirdly, if we buy stocks whose past prices increase acceleratively in the winner group but short all losers, as in Strategy 5, we should still obtain returns which are higher than the momentum profit but lower than the profit of Strategy 6. We can observe that the monthly raw return of Strategy 5 is 103.35 basis points. This is still higher than the momentum profit (Strategy 1) and the profit of Strategy 4 but lower than that of Strategy 6. Similarly, in Strategy 3 we buy all winner stocks and short stocks whose past prices decrease acceleratively in the loser group. The raw return of Strategy 3 is 112.32 basis points, which is higher than Strategies 1 and 2. In a nutshell, picking stocks based on their visual pattern is helpful for profit enhancement, even if it is one-sided. 


\section{[INSERT TABLE 2 HERE]}

In Panel B of Table 2, we conduct the mean difference tests and report the t-values to observe whether the average returns of these new strategies significantly outperform the momentum strategy in JT (1993). The results are overwhelming. Except for Strategies 2, 4, 7, and 9, which long-short the stocks with the "wrong" visual patterns, the other strategies all significantly outperform the momentum strategy, despite the inclusion or exclusion of January. In the untabulated results, we use alternative combinations of $(J, K)$. The basic results from Table 2 carry over. However, when $J$ is reduced, the profit difference between Strategies 1 and 6 also becomes smaller but remains significant. When the ranking period is smaller than 3 months, the profit difference between Strategies 1 and 6 becomes insignificant. This finding suggests that investors are more likely to use the visual pattern of stock prices over a long period rather than a short period as the reference. In summary, our conjectures discussed in Section 3.2 are all supported by the empirical evidence. Appendix 1 repeats Table 2 under $(J, K)=(24,6)$. In addition to the high profit of strategy 6 , the Sharpe ratio of Strategy $6(0.210)$ is double the ratio of Strategy 1 (0.095). 
4.2 Descriptive Characteristics of Stocks with Convex-shaped and Concave-shaped Past Prices

In addition to returns, Table 3 reports the main firm characteristics of the stocks when we sort them by past returns and the visual patterns of past prices. The raw numbers are presented in Panel A. It is perhaps more informative to compare the firms with convex-shaped and concave-shaped patterns of past prices with the entire stock universe. Hence, the $t$ values for tests of mean difference are shown in Panel B. We start with the two most important factors: size and book-to-market ratio. To calculate the average size, we first calculate the cross-sectional mean for each month, and then average the means across time. The other characteristics are calculated analogously. Size (in thousands) is defined as the product of beginning-of-the-month share price multiplied by the number of shares outstanding; volatility for each stock is calculated using the standard deviation of daily returns within the current month. We compute the daily bid-ask spread using only non-missing observations and then average the daily spread to become the monthly spread $^{6}$. To obtain monthly Amihud's illiquidity for each stock, we first calculate the

${ }^{6}$ Since the spread data are extracted from ISSM/TAQ, hence available starting in 1983, the bid-ask spread 21 
daily illiquidity measure - dividing the absolute return by the trading volume - and then average this daily quantity over the month (Amihud, 2002).

To begin, the firms which have convex-shaped past price patterns are, on average, the largest in all return quintiles, and the firms which have concave-shaped past price patterns are also larger than the universe. The differences are significant across all return quintiles, as shown in Panel B of Table 3, and for various ranking periods (untabulated). For example, the size of the winner stocks with highly convex-shaped past prices is $2,264,826$, and the size for all winner stocks is, on average, $1,442,020$. The $t$ value for the mean difference test between the two groups is 17.82. Compared to the differences in size, the differences in book-to-market ratio are mostly immaterial. In terms of volatility, the firms which have convex-shaped past price patterns are the least volatile across the market. But the firms which have concave-shaped past price patterns have a significantly higher volatility than the universe. Meanwhile, it appears that convex-shaped firms enjoy the smallest illiquidity, measured by the bid-ask spread and Amihud's illiquidity. For instance, the spread of the winner stocks with highly convex-shaped past prices is 1.44 , and the spread for all winner stocks is, on average, 1.91. The $t$ value for the mean difference test between the two groups is -41.20 . Regardless of return quintiles, the is only included in the regressions for 1984-2011. 
liquidity of the stocks with highly convex-shaped past prices, measured by either bid-ask spread or Amihud's illiquidity, is the highest.

Overall, compared to the universe, stocks with highly convex-shaped past prices are larger, less volatile, and more liquid. On the other hand, stocks with highly concave-shaped past prices are also larger and more liquid but more volatile than the universe. We also conduct tests of median difference for these firm characteristics under various combinations of ranking and holding periods. Our findings still hold under all of these alternative specifications.

\section{[INSERT TABLE 3 HERE]}

\section{Auxiliary Tests}

In this section, we use regression analyses to control for certain cross section return determinants. Several robustness checks are also performed.

\subsection{Fama-MacBeth Regressions}


We have already shown that, time-series wise, the returns from the new strategies cannot be subsumed by traditional risk factors. Insofar as momentum is a cross section phenomenon, we would like to see if our results still hold after controlling for certain firm characteristics. The strategy is to run Fama-MacBeth regressions using dummy variables.

In accordance with Table 2, we define four dummy variables - WinnerConvex, WinnerConcave, LoserConvex, and LoserConcave - all of which refer to the winner and loser groups in reference to a firm's visual pattern of past prices. For instance, if a stock is first sorted into the winner group and then sorted into the top 20\% group based on the coefficient $\gamma$ in equation (1) in a particular month, WinnerConvex $=1$ and zero otherwise. The other three dummy variables are defined analogously.

The control variables include firm size in the month (Size, in billion dollars), the book-to-market ratio $(B / M)$, total turnover in the month (Turnover), volatility in the month (Volatility), and the Amihud's illiquidity measure (Illiquidity). Moreover, we also include the lagged monthly return $\left(R_{\mathrm{t}-2}\right)$ to show that our results are not a simple manifestation of the monthly reversals presented by Jegadeesh (1990). For ease of exposition, we scale up the illiquidity measure by $10^{3}$. Notice that all variables are lagged by two months just as the monthly returns $\left(R_{\mathrm{t}-2}\right)$. The purpose is twofold. First, we use a 
two-month lag to avoid biases due to microstructure issues (Brennan, Chordia, and Subrahmanyam, 1998). Second, since we skip a month between the ranking and holding periods, at month $t$ we essentially use information up to month $t-2$ to form the portfolio. Aligning the control variables with the dummy variables in month $t-2$ enables us to rule out the possibility that our results are a simple recast of the monthly reversals in Jegadeesh (1990).

We average the coefficients from the cross section regressions and calculate $t$-values with the Newey-West adjustment. Altogether, we examine several specifications corresponding to different control variable inclusions. The analysis is performed for various ranking periods used in pattern recognition. For brevity, we only report two cases in Table 4: $J=12$ and $J=24$.

First of all, all the control variables have the expected signs and are mostly significant. More importantly, irrespective of the strong effects of all the control variables, the dummy variables WinnerConvex and LoserConcave are significantly positive and negative respectively. In other words, the observed return patterns in Table 2 remain strong even after we control for various firm characteristics. In addition, the variable LoserConvex becomes insignificant when the ranking period is extended. This suggests that convex-shaped losers become less salient for investors to short when the past returns 
in further time periods are examined.

\section{[INSERT TABLE 4 HERE]}

\subsection{Time Partition}

Cooper, Gutierrez, and Hameed (2004) find that the historical mean return to an equal-weighted momentum strategy has been $0.93 \%$ per month in up markets and $-0.37 \%$ per month in down markets. To investigate whether our findings are conditional on time, the performance of the nine strategies in three equal and non-overlapping sub-periods is examined. Table 5 presents the average monthly returns for the nine trading strategies.

\section{[INSERT TABLE 5 HERE]}

The evidence indicates that Strategy 6 always outperforms and Strategy 7 always underperforms other strategies in all sub-periods. In the last two decades, the profit of Strategy 6 achieves 98.53 basis points per month, approximately $12.49 \%$ annually. Although the profit of Strategy 6 remains significant, it is obvious that the profits of the 
other eight strategies become insignificant in the last two decades. Given the dotcom bubble and the subprime mortgage crisis in the last ten years, we follow Chordia and Shivakumar (2002) to analyze whether the profitability of these strategies is related to business cycles. Like Chordia and Shivakumar (2002), our sample is divided into two economic environments: expansionary and recessionary periods based on the NBER definition ${ }^{7}$. The returns of all strategies are examined in each of these environments.

The result in Table 5 corroborates the findings in Chordia and Shivakumar (2002) and Cooper, Gutierrez, and Hameed (2004). The profitability of all strategies is significantly positive during the expansionary period but insignificant during the recessionary period. Strategy 6 earns a significant profit of 154.83 basis points during the expansionary period but only an insignificant profit of 49 basis points during the recessionary period. Since each of the other eight strategies is a subset of the momentum strategy, it is natural to find that the profits of the eight strategies are only significant during the expansionary period.

5.3 Implementing the Strategies with Midpoints of Bid-Ask Quotes

${ }^{7}$ See http://www.nber.org/cycles.html 
Our main results are based on a one-month gap between the ranking and the holding periods. Therefore, potential microstructure issues are largely avoided. Nevertheless, to ensure that our results are not driven by bid-ask bounce, we repeat the analysis by replacing closing prices with the midpoints of closing bid and ask quotes, obtained from CRSP. Since CRSP only started reporting the closing quotes in the early 90s, our analysis here is for the period 1994-2011.

\section{[INSERT TABLE 6 HERE]}

Table 6 illustrates the results. It is seen that Strategy 6 still outperforms the momentum strategy (Strategy 1) by 56.45 basis points per month. The profit of Strategy 7 is also lower than the momentum strategy by 41.85 basis points per month. We also repeat the analysis in Table 5 and find that the outperformance of Strategy 6 obtained by using midpoints is not sensitive to time period either. Therefore, the outcome is that our results are not driven by bid-ask bounce.

\subsection{Exchange Subsamples}


In this section, the stocks are divided into NYSE/AMEX- and Nasdaq-based subsamples. There are two motives for doing this. First, insofar as momentum is a cross section phenomenon, we need to ascertain whether the argument for visual patterns holds true for different subsets of stocks. In other words, we need to demonstrate that the results hold up in alternative samples. Secondly, Lo, Mamaysky, and Wang (2000) find that certain technical patterns, when applied to many stocks over many time periods, do provide incremental information, especially for Nasdaq stocks. In this regard, our new strategies may work better on Nasdaq stocks.

Hence, we create two samples along the lines of exchange. We divide stocks into NYSE/AMEX- and Nasdaq-based subsamples. The relevant results are presented in Table 7. Panel A reports the returns for stocks listed in NYSE and AMEX and Panel B for stocks listed in Nasdaq.

We can observe that the findings in Table 2 apply fully to all subgroups regardless of where the stocks are listed. Similar to the previous finding, the profit of Strategy 6 sits at the top and Strategy 7 at the bottom. For example, Strategy 6 constructed by using stocks listed in NYSE/AMEX (Nasdaq) can yield 114.43 (152.21) basis points per month. Nevertheless, judging by the size of the raw returns as well as their $t$-values, Nasdaq stocks exhibit a much more impressive performance when we implement Strategy 6. One 
may infer that the better performance of Nasdaq stocks is due to their smaller size. The untabulated results do not support this inference, because the three-factor risk-adjusted return of Strategy 6 in the Nasdaq subsample is still significantly higher than in the NYSE/AMEX subsample $(t=3.86)$. This finding is not sensitive to the length of ranking/holding period. It is interesting to note that certain technical patterns do provide more incremental information for Nasdaq stocks, as Lo, Mamaysky, and Wang (2000) argue.

\section{[INSERT TABLE 7 HERE]}

\subsection{Reversals under Longer Holding Periods}

The duration of the risk-adjusted returns earned by one trading strategy is of interest to both academia and practitioners. Short-term (weekly) and long-term (3-5 years) reversals are documented by Lehmann (1990) and Jegadeesh (1990), and DeBondt and Thaler (1985) respectively. If the spectacular returns of these strategies result from intense investor attention, they should reverse themselves afterwards. To verify this, we recalculate the monthly profit for each strategy in Table 2 over various holding periods $(K)$ 
using overlapping portfolios, as in JT (1993). To conserve space, the ranking period $(J)$ is set at 6 . Essentially, we would like to see whether the average monthly returns go down substantially if we extend the holding period from one month to a longer period.

Table 8 presents the results. Two regularities can be observed. First, the profit of each strategy achieves a peak in the first month. Secondly, we can confirm the existence of reversals for a holding period of 36 months or longer. The profits of all strategies decline monotonically as we extend the holding period to 60 months. The overall evidence in this subsection confirms the salience of the attention-grabbing hypothesis.

\section{[INSERT TABLE 8 HERE]}

\subsection{Lagged One month, Data Filter, and Outliers}

In addition to the tests described above, we have also calculated the profits for all strategies (1) without skipping a month between the ranking and holding periods, (2) without removing stocks whose prices are below 5 dollars, and (3) after deleting stocks whose market capitalizations are in the smallest NYSE/AMEX/Nasdaq decile.

We find that the profits are higher without skipping one month, especially when the 
ranking period is long (e.g. $J>12$ ) and the holding period is short (e.g. $K<6$ ). Furthermore, deleting stocks which are priced below 5 dollars or whose market capitalizations are small at the beginning of the holding period will make the returns more significant, and the $\mathrm{R}^{2}$ increases marginally for the Fama-Macbeth regression in section 5.1. To conclude, our findings remain robust under all of the data winsorization, alternative specifications, and various ranking/holding periods.

\section{Conclusion}

This study provides fresh insights into stock return predictability by considering momentum portfolios from the perspective of investor attention. Specifically, we analyze how the graph of past prices of a stock looks; that is, we identify the visual pattern of past prices. Given that momentum is induced by cognitive bias, we can expect that investors will be attracted to the stocks whose patterns of past prices grab their attention. In other words, recognizing the pattern of past prices should provide incremental information and enhance profit.

We design a few alternative momentum strategies that transact in only a subset of the stocks in the winner and loser portfolios. The empirical results substantiate our 
conjecture. Buying winner stocks whose past price patterns are extremely convex-shaped and shorting loser stocks whose past price patterns are extremely concave-shaped produces the highest return. As an illustration, the new improved strategy generates an annual raw return of $17.11 \%$ (132.46 basis points) and a Sharpe ratio of 0.260 in the period 1962 to 2011. The corresponding momentum strategy generates an annual raw return of $10.46 \%$ and a Sharpe ratio of 0.204 . The new strategy can enhance the profit by 64\%. Our findings are also robust to sample division into subperiods, replacing closing prices with the midpoints of closing bid and ask quotes, removing January returns, and various exchanges.

The much improved profits and Sharpe ratios are not the only features of the improved strategies. Since our strategies involve only a subset of the winner/loser portfolios, they call for transactions in only two hundred or so stocks, in contrast to the almost one or two thousand stocks required by the conventional momentum strategy. Our new strategy is feasible and easy to implement. Therefore, our study has immediate and profound investment implications for practice, especially for hedge funds.

More importantly, our study also makes a conceptual contribution. Momentum and reversals in stock returns directly contradict the market efficiency hypothesis and pose a challenge to the asset pricing field. As a result, researchers have developed various 
theories to explain the puzzle or anomaly. The profession is far from reaching a consensus as to whether the cross-sectional return predictability is a violation of market efficiency or a simple manifestation of certain rational valuation mechanisms that have eluded all to the present day. The fact that picking stocks which have special visual patterns of past prices can generate higher returns seems to fuel much of the market efficiency debate and poses a significant challenge to any attempt to rationalize the phenomenon from a rational perspective. 


\section{REFERENCES}

Ally, Brandon A., Carl A. Gold, and Andrew E. Budson, 2009, The picture superiority effect in patients with Alzheimer's disease and mild cognitive impairment, Neuropsychologia 47, 595-598.

Amihud, Yakov, 2002, Illiquidity and stock returns: Cross-section and time-series effects, Journal of Financial Markets 5, 31-56.

Anderson, John R., 2004, Cognitive Psychology and Its Implications, $6^{\text {th }}$ ed., Worth Publishers.

Asness, Clifford S., Tobias J. Moskowitz, and Lasse Heje Pedersen, 2009, Value and momentum everywhere, Working paper.

Avramov, Doron, Tarun Chordia, Gergana Jostova, and Alexander Philipov, 2007, Momentum and credit rating, Journal of Finance 62, 2503-2520.

Barber, Brad M. and Terrance Odean, 2008, All that glitters: The effect of attention and news on the buying behavior of individual and institutional investors, Review of Financial Studies 21, 785-818.

Barberis, Nicholas, Andrei Shleifer, and Robert Vishny, 1998, A model of investor sentiment, Journal of Financial Economics 49, 307-343.

Berk, Jonathan B., Richard C. Green, and Vasant Naik, 1999, Optimal investment, growth options, and security returns, Journal of Finance 54, 1553-1607.

Brennan, Michael J., Tarun Chordia, and Avanidhr Subrahmanyam, 1998, Alternative factor specifications, security characteristics, and the cross-section of expected stock returns, Journal of Financial Economics 49, 345-373.

Chan, Louis, Narasimhan Jegadeesh, and Josef Lakonishok, 1996, Momentum strategies, Journal of Finance 51, 1681-1713.

Chordia, Tarun and Lakshmanan Shivakumar, 2002, Momentum, business cycle, and time-varying expected returns, Journal of Finance 57, 985-1029.

Conrad, Jennifer and Gautam Kaul, 1998, An anatomy of trading strategies, Review of Financial Studies 11,489-519. 
Cooper, Michael J., Roberto C. Gutierrez Jr., and Allaudeen Hameed, 2004, Market states and momentum, Journal of Finance 59, 1345-1365.

Curran, Tim and Jeanne Doyle, 2011, Picture superiority doubly dissociates the ERP correlates of recollection and familiarity, Journal of Cognitive Neuroscience 23, 1247-1262.

Daniel, Kent, David Hirshleifer, and Avanidhar Subrahmanyam, 1998, Investor psychology and security market under- and overreactions, Journal of Finance 53, 1839-1885.

DeBondt, Werner F. M. and Richard Thaler, 1985, Does the stock market overreact? Journal of Finance 40, 793-805.

Defetyer, Margaret A., Riccardo Russo, and Pamela L. McPartlin, 2009, The picture superiority effect in recognition memory: A developmental study using the response signal procedure, Cognitive Development 24, 265-273.

Doukas, John A. and Phillip J. McKnight, 2005, European momentum strategies, information diffusion and investor conservatism, European Financial Management 11, 313-338.

George, Thomas J. and Chuan-Yang Hwang, 2004, The 52-week high and momentum investing, Journal of Finance 59, 2145-2176.

Hameed, Allaudeen, Joshua Huang, and Mujtaba G. Mian, 2010, Industries and stock return reversals, Working paper.

Hirshleifer, David, Kewei Hou, and Siew Hong Teoh, 2012, The accrual anomaly: Risk or mispricing, Management Science 58, 320-335.

Hong, Harrison and Jeremy C. Stein, 1999, A unified theory of underreaction, momentum trading and overreaction in asset markets, Journal of Finance 54, 2143-2184.

Hong, Harrison, Terence Lim, and Jeremy C. Stein, 2000, Bad news travels slowly: Size, analyst coverage, and the profitability of momentum strategies, Journal of Finance 55, 265-295.

Hou, Kewei, Lin Peng, and Wei Xiong, 2009, A tale of anomalies: the implications of investor attention for price and earnings momentum, Working Paper.

Jegadeesh, Narasimhan, 1990, Evidence of predictable behavior in security prices, 
Journal of Finance 45, 881-898.

Jegadeesh, Narasimhan and Sheridan Titman, 2001, Profitability of momentum strategies:

An evaluation of alternative explanations, Journal of Finance 56, 699-720.

Jegadeesh, Narasimhan and Sheridan Titman, 1993, Returns to buying winners and selling losers: Implications for stock market efficiency, Journal of Finance 48, 65-91.

Kahneman, Daniel, 1973, Attention and Effort, Prentice Hall.

Lehmann, Bruce N., 1990, Fads, martingales, and market efficiency, Quarterly Journal of Economics 105, 1-28.

Li , Jun and Jianfeng Yu, 2012, Investor attention, psychological anchors, and stock return predictability, Journal of Financial Economics 104, 401-419.

Lo, Andrew W. and Craig A. MacKinlay, 2001, A Non-random Walk Down Wall Street, Princeton University Press.

Lo, Andrew W. and Craig A. MacKinlay, 1988, Stock market prices do not follow random walks: Evidence from a simple specification test, Review of Financial Studies 1, 41-66.

Lo, Andrew W., Harry Mamaysky, and Jiang Wang, 2000, Foundations of technical analysis: Computational algorithms, statistical inference and implementation, Journal of Finance 55, 1705-1770.

McBride, Dawn M. and Barbara A. Dosher, 2002, A comparison of conscious and automatic memory processes for picture and word stimuli: A process dissociation analysis, Consciousness and Cognition 11, 423-460.

Moskowitz, Tobias J. and Mark Grinblatt, 1999, Do industries explain momentum? Journal of Finance 54, 1249-1290.

Paivio, Allan, 1986, Mental Representations: A Dual-coding Approach, New York: Oxford University Press.

Paivio, Allan, 1971, Imagery and Verbal Processes, New York: Holt, Rinehart, and Winston.

Rouwenhorst, Geert K., 1998, International momentum strategies, Journal of Finance 53, 267-284. 
Shepard, Roger N., 1967, Recognition memory for words, sentences, and pictures, Journal of Learning and Verbal Behavior 6, 156-163.

Shumway, Tyler, 1997, The delisting bias in CRSP data, Journal of Finance 52, 327-340. Wei, Jason, and Liyan Yang, 2012, Short-term momentum and reversals in large stocks, Working paper.

Whitehouse, Andrew J. O., Murray T. Maybery, Kevin Durkin, 2006, The development of the picture-superiority effect, British Journal of Developmental Psychology 24, 767-773. 
Table 1 The Zero-investment Portfolios of Stocks Sorted by Convexity in the Winner and Loser Groups

This table reports the average monthly returns in basis points of portfolios from January 1962 to December 2011. The sample includes all common stocks listed in NYSE, AMEX, and Nasdaq. At the time of sorting and portfolio formation, stocks with a share price of \$5 or lower are deleted. Stocks are first sorted to quintiles based on the past $J$-month returns lagged one month. We then regressing the daily prices in the past $J$ months on the variable $t$ and the square of $t$ for each stock, where $t$ is an arithmetic sequence, which is equal to $1,2,3 \ldots$ or $n$ for the indication of the past $n, \ldots, 3,2$, or 1 day respectively. In the winner group (top 20\%) and loser group (bottom 20\%), the stocks are sorted to quintiles based on the coefficients of the square of $t$. All equally-weighted portfolios are held for $K$ months. Each cell in this table reports the monthly raw return of buying the stocks whose coefficients of the square of $t$ are the top 20\% and selling the stocks whose coefficients of the square of $t$ are the bottom 20\% under alternative ranking $(J)$ and holding $(K)$ periods in the winner (Panel A) and loser groups (Panel B). The $t$-statistics in parentheses are corrected for autocorrelation by the Newey-West procedure. Bolded $t$-values correspond to a significance level of $5 \%$ or higher.

\begin{tabular}{|c|c|c|c|c|c|c|c|c|c|c|c|c|c|}
\hline \multirow[b]{2}{*}{$\mathrm{J}$} & \multirow[b]{2}{*}{$\mathrm{K}=$} & \multicolumn{6}{|c|}{ Panel A. Winner Group } & \multicolumn{6}{|c|}{ Panel B. Loser Group } \\
\hline & & 1 & 2 & 3 & 6 & 9 & 12 & 1 & 2 & 3 & 6 & 9 & 12 \\
\hline \multirow[t]{2}{*}{3} & & 14.06 & 18.17 & 10.68 & 8.73 & 6.66 & 7.98 & -8.09 & 6.98 & 0.66 & 4.27 & -1.09 & 4.84 \\
\hline & & $(1.21)$ & (2.53) & $(2.04)$ & (3.00) & (2.60) & (3.71) & $(-0.61)$ & $(0.86)$ & $(0.11)$ & $(1.27)$ & $(-0.38)$ & (1.96) \\
\hline \multirow[t]{2}{*}{6} & & 10.12 & 4.53 & 5.38 & 8.90 & 18.33 & 17.16 & -9.00 & -4.07 & 3.37 & 2.11 & 11.40 & 12.62 \\
\hline & & $(0.90)$ & $(0.49)$ & $(0.71)$ & (1.63) & (3.94) & $(4.95)$ & $(-0.63)$ & $(-0.29)$ & $(0.31)$ & $(0.39)$ & $(2.80)$ & (3.55) \\
\hline \multirow[t]{2}{*}{9} & & 16.81 & 19.92 & 16.95 & 28.75 & 33.07 & 27.61 & 9.19 & 18.76 & 13.99 & 13.52 & 27.21 & 23.37 \\
\hline & & $(1.45)$ & $(1.74)$ & $(1.55)$ & (3.31) & $(4.96)$ & (5.35) & $(0.81)$ & $(1.83)$ & $(1.48)$ & $(1.81)$ & (4.65) & (4.77) \\
\hline \multirow[t]{2}{*}{12} & & 47.39 & 44.78 & 49.29 & 54.44 & 50.08 & 37.37 & -8.47 & 0.98 & 11.88 & 31.22 & 39.03 & 34.57 \\
\hline & & (3.67) & (3.57) & (4.11) & (5.49) & (6.26) & (5.59) & $(-0.67)$ & $(0.08)$ & (1.03) & (3.22) & (5.24) & (5.72) \\
\hline \multirow[t]{2}{*}{24} & & 87.56 & 83.03 & 76.71 & 63.09 & 49.97 & 38.50 & 69.99 & 76.81 & 75.10 & 69.14 & 60.65 & 49.63 \\
\hline & & $(5.45)$ & $(5.22)$ & $(4.97)$ & (4.18) & (3.45) & $(2.94)$ & (4.64) & (5.19) & (5.12) & (5.13) & $(4.95)$ & (4.66) \\
\hline \multirow[t]{2}{*}{36} & & 68.16 & 61.24 & 57.91 & 48.85 & 40.65 & 31.92 & 75.95 & 73.05 & 68.48 & 54.28 & 40.03 & 29.44 \\
\hline & & (3.63) & (3.31) & (3.17) & (2.88) & (2.64) & (2.31) & (4.31) & (4.53) & (4.33) & (3.83) & (3.15) & (2.55) \\
\hline \multirow[t]{2}{*}{48} & & 60.10 & 56.08 & 51.53 & 39.76 & 32.49 & 26.64 & 43.78 & 39.15 & 32.97 & 18.91 & 9.90 & 6.00 \\
\hline & & (3.57) & (3.36) & (3.10) & (2.54) & (2.31) & (2.09) & (2.45) & (2.26) & (1.90) & (1.13) & $(0.64)$ & $(0.41)$ \\
\hline \multirow[t]{2}{*}{60} & & 42.40 & 43.09 & 39.53 & 30.56 & 22.93 & 16.71 & 26.63 & 18.34 & 14.70 & 10.89 & 5.39 & 4.34 \\
\hline & & $(2.40)$ & (2.62) & (2.43) & (2.06) & (1.66) & (1.30) & (1.57) & (1.13) & (0.95) & $(0.74)$ & (0.39) & (0.33) \\
\hline
\end{tabular}


Table 2 Performance of Trading Strategies Estimated by Simple Raw Returns and Risk-Adjusted Returns

This table reports the average monthly returns, the $t$-values, and the Sharpe ratios for nine trading strategies from January 1962 to December 2011. The sample includes all common stocks listed in NYSE, AMEX, and Nasdaq. At the time of sorting and portfolio formation, stocks with a share price of $\$ 5$ or lower are deleted. For brevity, stocks are sorted to quintiles based on the past 12-month returns lagged one month. All equally-weighted portfolios are held for 6 month. The convexity and concavity for each stock are defined by regressing the daily prices in the past 12 months on the variable $t$ and the square of $t$ for each stock, where $t$ is an arithmetic sequence, which is equal to $1,2,3 \ldots$ or $n$ for the indication of the past $n, \ldots, 3,2$, or 1 day respectively. Stocks whose coefficients of the square of $t$ are the top $20 \%$ are those with highly convex-shaped past prices; conversely, stocks whose coefficients of the square of $t$ are the bottom $20 \%$ are those with highly concave-shaped past prices. The nine trading strategies are constructed by buying and selling the stocks with different visual patterns of past prices. Panel A presents the returns in basis points, the $t$-values, and the Sharpe ratios of the nine trading strategies. The Sharpe ratio in brackets is defined as dividing the excess return of a portfolio by the standard deviation of this excess return. For alphas, the Sharpe ratio is actually the appraisal ratio: alpha divided by the idiosyncratic volatility of the portfolio returns. The $t$-statistics in parentheses are adjusted for autocorrelation using the Newey-West covariance matrix. For Panel B, the $t$-statistics in parentheses examine whether the performance difference between two different portfolios is significantly different from zero, and Bolded $t$-values correspond to a significance level of $5 \%$ or higher. 


\begin{tabular}{|c|c|c|c|c|c|c|c|}
\hline \multicolumn{8}{|c|}{ Panel A. Portfolio Return } \\
\hline & & \multicolumn{3}{|c|}{ Raw Return } & \multicolumn{3}{|c|}{ Alphas from the Fama-FrenchThree-factor Model } \\
\hline Trading Strategy & & All Months & January Only & January Excluded & All Months & January Only & January Excluded \\
\hline \multirow{2}{*}{ 1. Long (Winner) } & T-value & (4.77) & $(-2.44)$ & (5.65) & (7.55) & $(-0.70)$ & (8.17) \\
\hline & Sharpe ratio & [0.204] & {$[-0.375]$} & [0.268] & [0.204] & {$[-0.375]$} & [0.268] \\
\hline \multirow[t]{2}{*}{ Short (Highly Convex in Loser) } & T-value & $(4.43)$ & $(-1.78)$ & (5.27) & (6.63) & $(-0.48)$ & (7.46) \\
\hline & Sharpe ratio & [0.197] & {$[-0.296]$} & [0.249] & [0.197] & {$[-0.296]$} & {$[0.249]$} \\
\hline \multirow[b]{2}{*}{ Short (Highly Concave in Loser) } & Return(bp) & 112.32 & -72.17 & 128.75 & 146.09 & 27.96 & 160.03 \\
\hline & T-value & (6.35) & $(-1.08)$ & (6.69) & (8.30) & $(0.39)$ & $(8.70)$ \\
\hline Short (Loser) & T-value & (2.66) & $(-3.14)$ & (3.68) & (5.97) & $(-1.53)$ & (6.81) \\
\hline & Sharpe ratio & [0.121] & {$[-0.517]$} & [0.193] & {$[0.121]$} & {$[-0.517]$} & [0.193] \\
\hline 5. Long (Highly Convex in Winner) & Return(bp) & 103.35 & -232.74 & 133.28 & 151.75 & -70.63 & 173.09 \\
\hline Short (Loser) & T-value & (5.29) & $(-3.22)$ & (6.37) & (7.91) & $(-0.92)$ & (8.53) \\
\hline & Sharpe ratio & {$[0.221]$} & {$[-0.434]$} & [0.297] & {$[0.221]$} & {$[-0.434]$} & {$[0.297]$} \\
\hline 6. Long (Highly Convex in Winner) & Return(bp) & 132.46 & -133.52 & 156.14 & 174.70 & 9.56 & 193.50 \\
\hline Short (Highly Concave in Loser) & T-value & (6.56) & $(-1.88)$ & (6.99) & (8.44) & $(0.12)$ & $(8.80)$ \\
\hline \multirow[t]{3}{*}{ 8. Long (Highly Convex in Winner) } & Return(bp) & 101.25 & -195.80 & 127.71 & 145.82 & -58.70 & 165.32 \\
\hline & T-value & (5.12) & $(-2.63)$ & (6.18) & (7.41) & $(-0.71)$ & (8.25) \\
\hline & Sharpe ratio & {$[0.221]$} & {$[-0.381]$} & {$[0.288]$} & {$[0.221]$} & {$[-0.381]$} & {$[0.288]$} \\
\hline \multirow{3}{*}{$\begin{array}{l}\text { 9. Long (Highly Concave in Winner) } \\
\text { Short (Highly Concave in Loser) }\end{array}$} & Return(bp) & 78.00 & -141.99 & 97.59 & 116.40 & -43.74 & 131.18 \\
\hline & T-value & (4.49) & $(-2.16)$ & (5.25) & (7.23) & $(-0.59)$ & (7.99) \\
\hline & Sharpe ratio & [0.191] & {$[-0.265]$} & {$[0.250]$} & {$[0.191]$} & {$[-0.265]$} & {$[0.250]$} \\
\hline
\end{tabular}




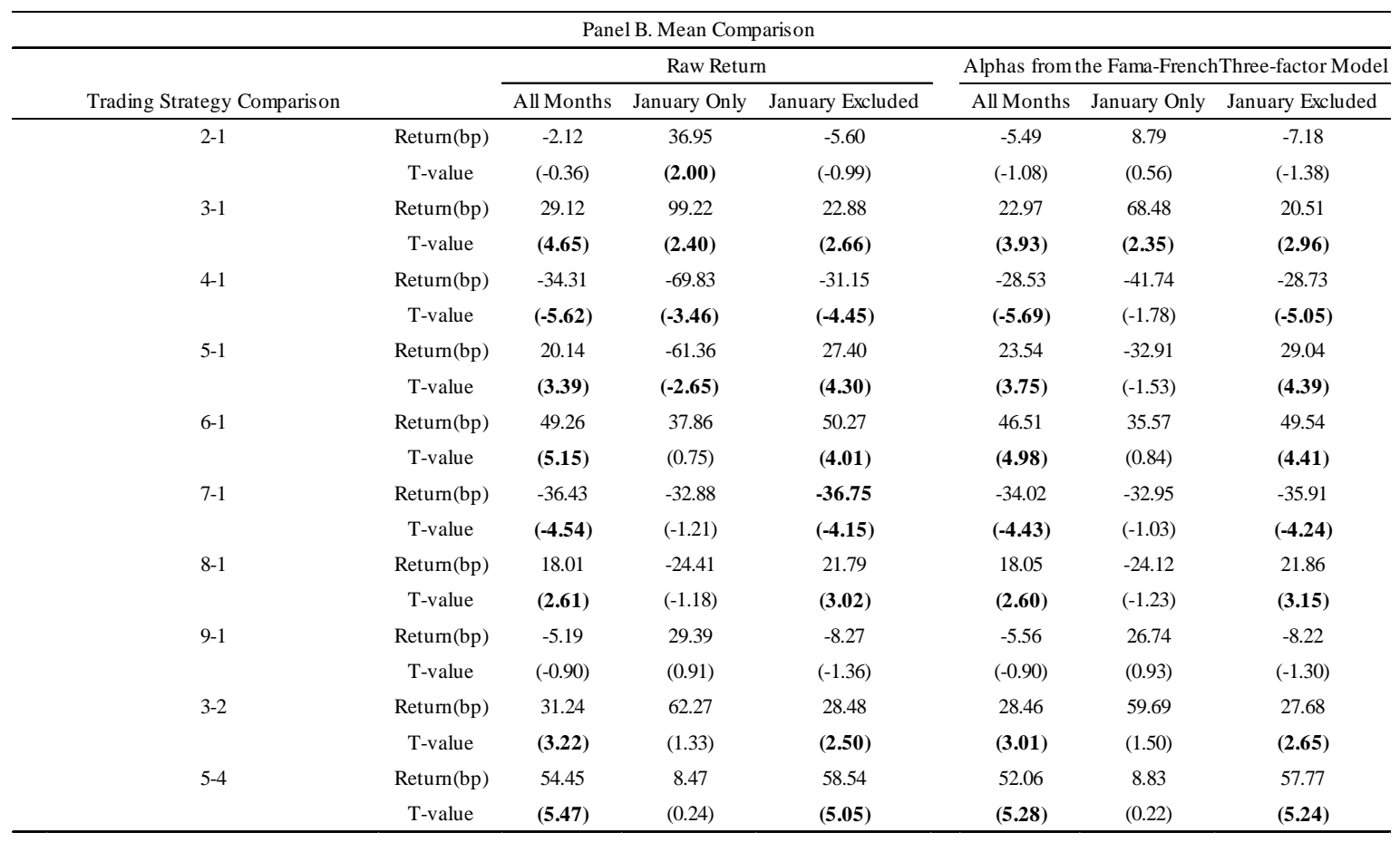


Table 3 Firm Characteristics of Stocks in Different Return and Convexity Quintiles

This table presents the firm characteristics of the stocks under the double partition of past returns and the convexity of past prices. The sample covers all common stocks listed in NYSE, AMEX, and Nasdaq from January 1962 to December 2011. At the time of sorting and portfolio formation, stocks with a share price of $\$ 5$ or lower are deleted. We first sort stocks into quintiles based on the past 12-month returns. In each return quintile, stocks are sorted to quintiles based on the coefficients of the square of $t$ obtained by regressing the daily prices in the past 12 months on the variable $t$ and the square of $t$ for each stock. In total, there are 25 portfolios. Panel A presents the average firm size, book-to-market ratios, volatility, bid-ask spread, and Amihud's illiquidity measure for the 25 portfolios. For each category of stocks, a cross-sectional monthly mean is found for each month, and then the mean size is averaged across time to obtain the final average. Firm size (in thousand dollars) is the product of the number of shares outstanding and the stock price. Monthly volatility is calculated using daily prices within each portfolio formation month. Bid-ask spread is measured as dividing the difference between ask and bid by the midpoint of bid and ask. Monthly illiquidity measure for each stock is computed as dividing the daily absolute return by the daily trading volume and then averaging this daily quantity over the month. Panel B presents the $t$-values for the mean-difference test between different categories of stocks and between the universe and a category of stocks. Bolded $t$-values correspond to a significance level of $5 \%$ or higher. 


\begin{tabular}{|c|c|c|c|c|c|c|c|c|c|}
\hline \multicolumn{7}{|c|}{ Panel A. Firm Characteristics } & \multicolumn{3}{|c|}{ Panel B. T Values for Tests of Mean Difference } \\
\hline & \multicolumn{5}{|c|}{ Size } & \multirow[b]{2}{*}{ All } & \multicolumn{3}{|c|}{ Size } \\
\hline & Highly Concave & 2 & 3 & 4 & Highly Convex & & Mean difference test (Convex-Concave) & Mean difference test (Concave-Universe) & Mean difference test (Convex-Universe \\
\hline Loser & $1,311,357$ & 754,987 & 655,546 & 846,833 & $1,396,791$ & 993,169 & 2.01 & 9.72 & 12.64 \\
\hline 2 & $2,357,059$ & $1,341,669$ & $1,037,714$ & $1,293,544$ & $2,612,533$ & $1,728,722$ & 4.01 & 13.62 & 17.62 \\
\hline 3 & 2,858,238 & $1,453,602$ & $1,295,574$ & $1,532,312$ & 3,102,698 & $2,048,684$ & 3.55 & 15.79 & 20.02 \\
\hline 4 & 2,933,226 & $1,534,112$ & $1,250,878$ & $1,532,945$ & 3,187,961 & $2,087,936$ & 3.33 & 14.94 & 18.86 \\
\hline Winner & $2,224,354$ & 958,870 & 787,400 & 974,338 & 2,264,826 & $1,442,020$ & 0.64 & 16.21 & 17.82 \\
\hline \multicolumn{7}{|c|}{ Book-to-market Ratio } & \multicolumn{3}{|c|}{ Book-to-market Ratio } \\
\hline & Highly Concave & 2 & 3 & 4 & Highly Convex & All & Mean difference test (Convex-Concave) & Mean difference test (Concave-Universe) & Mean difference test (Convex-Universe \\
\hline Loser & 1.09 & 0.70 & 4.32 & 0.85 & 0.44 & 1.48 & -2.04 & -0.51 & -1.51 \\
\hline 2 & 0.82 & 14.44 & 4.99 & 1.00 & 7.25 & 5.70 & 1.37 & -2.71 & 0.31 \\
\hline 3 & 1.35 & 4.32 & 1.20 & 4.24 & 0.65 & 2.34 & -2.02 & -0.97 & -1.76 \\
\hline 4 & 7.04 & 0.95 & 0.93 & 0.98 & 1.05 & 2.20 & -1.24 & 0.99 & -0.90 \\
\hline Winner & 3.19 & 2.20 & 2.05 & 1.34 & 1.86 & 2.13 & -0.85 & 0.84 & -0.24 \\
\hline \multicolumn{7}{|c|}{ Volatility } & \multicolumn{3}{|c|}{ Volatility } \\
\hline & Highly Concave & 2 & 3 & 4 & Highly Convex & All & Mean difference test (Convex-Concave) & Mean difference test (Concave-Universe) & Mean difference test (Convex-Universe \\
\hline Loser & 0.03 & 0.03 & 0.03 & 0.03 & 0.03 & 0.03 & -21.73 & 13.64 & -14.23 \\
\hline 2 & 0.02 & 0.02 & 0.02 & 0.02 & 0.02 & 0.02 & -23.52 & 10.59 & -20.01 \\
\hline 3 & 0.02 & 0.02 & 0.02 & 0.02 & 0.02 & 0.02 & -22.11 & 10.08 & -18.59 \\
\hline 4 & 0.02 & 0.02 & 0.02 & 0.02 & 0.02 & 0.02 & -20.89 & 7.40 & -19.69 \\
\hline Winner & 0.03 & 0.03 & 0.03 & 0.03 & 0.03 & 0.03 & -3.50 & -3.63 & -7.95 \\
\hline
\end{tabular}




\begin{tabular}{|c|c|c|c|c|c|c|c|c|c|}
\hline \multicolumn{7}{|c|}{ Panel A. Firm Characteristics } & \multicolumn{3}{|c|}{ Panel B. T Values for Tests of Mean Difference } \\
\hline & \multicolumn{5}{|c|}{ Bid-ask Spread } & & \multicolumn{3}{|c|}{ Bid-ask Spread } \\
\hline & Highly Concave & 2 & 3 & 4 & Highly Convex & All & Mean difference test (Convex-Concave) & Mean difference test (Concave-Universe) & Mean difference test (Convex-Universe) \\
\hline Loser & 2.38 & 3.08 & 3.22 & 2.93 & 2.16 & 2.75 & -11.29 & -23.46 & -39.79 \\
\hline 2 & 1.95 & 2.69 & 2.90 & 2.67 & 1.82 & 2.41 & -7.59 & -31.87 & -43.06 \\
\hline 3 & 1.78 & 2.44 & 2.62 & 2.40 & 1.63 & 2.18 & -9.37 & -30.42 & -43.29 \\
\hline 4 & 1.70 & 2.28 & 2.47 & 2.24 & 1.55 & 2.05 & -10.02 & -27.43 & -41.45 \\
\hline Winner & 1.69 & 2.16 & 2.23 & 2.01 & 1.44 & 1.91 & -16.65 & -17.93 & -41.20 \\
\hline \multicolumn{7}{|c|}{ Illiquidity } & \multicolumn{3}{|c|}{ Illiquidity } \\
\hline & Highly Concave & 2 & 3 & 4 & Highly Convex & All & Mean difference test (Convex-Concave) & Mean difference test (Concave-Universe) & Mean difference test (Convex-Universe) \\
\hline Loser & 10.73 & 16.53 & 17.66 & 15.11 & 9.66 & 13.92 & $\begin{array}{l}-2.32 \\
\end{array}$ & $\begin{array}{l}-8.65 \\
\end{array}$ & -11.16 \\
\hline 2 & 11.29 & 17.89 & 20.51 & 17.55 & 10.19 & 15.45 & -2.09 & -8.94 & -14.36 \\
\hline 3 & 10.64 & 16.73 & 18.79 & 16.21 & 9.70 & 14.38 & -2.10 & -9.77 & -13.42 \\
\hline 4 & 9.84 & 14.50 & 15.84 & 15.06 & 9.19 & 12.86 & -1.49 & -7.89 & -11.11 \\
\hline Winner & 8.15 & 11.20 & 11.34 & 10.77 & 7.09 & 9.70 & -3.41 & -5.09 & -13.63 \\
\hline
\end{tabular}




\section{Table 4 Fama-MacBeth Regressions to Control for Other Return Determinants}

This table presents the results from Fama-MacBeth regressions. The sample covers all common stocks listed in NYSE, AMEX, and Nasdaq from January 1962 to December 2011. Stocks with a share price of \$5 or lower at the time of sorting and portfolio formation are deleted. Each month, we cross-sectionally regress returns on the convex-shaped and concave-shaped dummy variables while controlling for firm size (Size), book-market ratio (B/M ratio), turnover (Turnover), Amihud's illiquidity measure (Illiquidity), past 2-month return $\left(\mathrm{R}_{\mathrm{t}-2}\right)$. Like the past return $\left(\mathrm{R}_{\mathrm{t}-2}\right)$, all other control variables are also lagged for two periods. The time-series average for each variable is reported. The illiquidity measure is scaled up by $10^{3}$ and firm size is in billion dollars. For dummy variables are included. At the beginning of each month, stocks are sorted to quintiles based on the past 12-month returns in Panel A and past 24-month returns in Panel B. In each return quintile, stocks are sorted to quintiles based on the coefficients of the square of $t$ obtained by regressing the daily prices in the past 12 months on the variable $t$ and the square of $t$ for each stock. The variable WinnerConvex is one if the stock is classified to the top $20 \%$ based on the ranking of the coefficient of the square of $t$ in the winner group (top 20\% based on the past 12-month returns) and zero otherwise. By the same token, the variable LoserConcave is one if the stock belongs to the loser group (bottom $20 \%$ based on the past 12-month returns) and is ranked to the bottom $20 \%$ based on the ranking of the coefficient of the square of $t$. The other two dummy variables are defined analogously. The $t$-statistics in parentheses are adjusted for autocorrelation using the Newey-West covariance matrix. Bolded t-values correspond to a significance level of $5 \%$ or higher. 


\begin{tabular}{|c|c|c|c|c|}
\hline \multicolumn{5}{|c|}{ Panel A. J=12 } \\
\hline & (1) & (2) & (3) & (4) \\
\hline \multirow[t]{2}{*}{ Intercept } & 0.0112 & 0.0122 & 0.0117 & 0.0126 \\
\hline & (3.65) & (5.24) & (3.81) & (5.42) \\
\hline \multirow[t]{2}{*}{ Size } & -0.2690 & -0.2460 & -0.2768 & -0.2555 \\
\hline & $(-1.76)$ & $(-2.41)$ & $(-1.90)$ & $(-2.58)$ \\
\hline \multirow[t]{2}{*}{ B/M Ratio } & 0.0022 & 0.0017 & 0.0021 & 0.0016 \\
\hline & (3.85) & (3.08) & (3.69) & (3.02) \\
\hline \multirow[t]{2}{*}{ Turnover } & & 0.0025 & & 0.0017 \\
\hline & & $(0.30)$ & & $(0.22)$ \\
\hline \multirow[t]{2}{*}{ Volatility } & & -0.0534 & & -0.0512 \\
\hline & & $(-1.07)$ & & $(-1.04)$ \\
\hline \multirow[t]{2}{*}{ Illiquidity } & & 0.0269 & & 0.0248 \\
\hline & & (2.19) & & (2.08) \\
\hline \multirow[t]{2}{*}{ Rt-2 } & & 0.0007 & & -0.0012 \\
\hline & & $(0.24)$ & & $(-0.39)$ \\
\hline \multirow[t]{2}{*}{ WinnerConvex } & & & 0.0047 & 0.0058 \\
\hline & & & (2.80) & (4.20) \\
\hline \multirow[t]{2}{*}{ WinnerConcave } & & & 0.0002 & 0.0010 \\
\hline & & & $(0.10)$ & $(0.70)$ \\
\hline \multirow[t]{2}{*}{ LoserConvex } & & & -0.0097 & -0.0087 \\
\hline & & & $(-7.61)$ & $(-7.41)$ \\
\hline \multirow[t]{2}{*}{ LoserConcave } & & & -0.0087 & -0.0084 \\
\hline & & & $(-7.41)$ & $(-8.02)$ \\
\hline \multirow[t]{2}{*}{ Average R-square } & 0.01 & 0.04 & 0.01 & 0.04 \\
\hline & & anel B. J= & & \\
\hline \multirow{3}{*}{ Intercept } & (1) & (2) & (3) & (4) \\
\hline & 0.0112 & 0.0122 & 0.0115 & 0.0124 \\
\hline & (3.65) & (5.24) & (3.69) & (5.28) \\
\hline \multirow[t]{2}{*}{ Size } & -0.2690 & -0.2460 & -0.3006 & -0.2766 \\
\hline & $(-1.76)$ & $(-2.41)$ & $(-2.05)$ & $(-2.77)$ \\
\hline \multirow[t]{2}{*}{ B/M Ratio } & 0.0022 & 0.0017 & 0.0022 & 0.0016 \\
\hline & (3.85) & (3.08) & (3.86) & (3.15) \\
\hline \multirow[t]{2}{*}{ Turnover } & & 0.0025 & & 0.0016 \\
\hline & & $(0.30)$ & & $(0.21)$ \\
\hline \multirow[t]{2}{*}{ Volatility } & & -0.0534 & & -0.0515 \\
\hline & & $(-1.07)$ & & $(-1.03)$ \\
\hline \multirow[t]{2}{*}{ Illiquidity } & & 0.0269 & & 0.0265 \\
\hline & & (2.19) & & (2.18) \\
\hline \multirow[t]{2}{*}{$\mathrm{R}_{\mathrm{t}-2}$} & & 0.0007 & & -0.0004 \\
\hline & & $(0.24)$ & & $(-0.12)$ \\
\hline \multirow[t]{2}{*}{ WinnerConvex } & & & 0.0055 & 0.0058 \\
\hline & & & (3.08) & (3.91) \\
\hline \multirow[t]{2}{*}{ WinnerConcave } & & & -0.0024 & -0.0013 \\
\hline & & & $(-1.64)$ & $(-1.04)$ \\
\hline LoserConvex & & & -0.0014 & -0.0008 \\
\hline & & & $(-1.12)$ & $(-0.72)$ \\
\hline LoserConcave & & & -0.0082 & -0.0076 \\
\hline & & & $(-6.01)$ & $(-6.19)$ \\
\hline Average R-square & 0.01 & 0.04 & 0.01 & 0.04 \\
\hline
\end{tabular}




\section{Table 5 Performance of Trading Strategies Conditional on Time}

This table presents the monthly raw returns, the $t$-values, and the Sharpe ratios for nine trading strategies in three non-overlapping sub-periods. The holding periods that are also classified into two business cycles, expansionary and contractionary determined by the NBER (www.nber.org/cycles.html).The sample includes all common stocks listed in NYSE, AMEX, and Nasdaq ranging from January 1962 to December 2011. Stocks whose share prices are lower than $\$ 5$ at the time of sorting and portfolio formation are deleted. The ranking period is 12 months lagged one month and the holding period is 6 months. Panel A reports the average monthly returns in basis points, the t-values and Sharpe ratios. Sharpe ratios are calculated using monthly portfolio excess returns and standard deviations. Panel B reports the $t$-statistics (in parentheses) for the mean-difference test of returns between different trading strategies. The $t$-statistics are corrected for autocorrelation using the Newey-West procedure. Bolded $t$-values correspond to a significance level of $5 \%$ or higher. 


\begin{tabular}{|c|c|c|c|c|c|c|}
\hline \multicolumn{7}{|c|}{ Panel A. Raw Returns } \\
\hline \multicolumn{2}{|l|}{ Trading Strategy } & 196201-197808 & 1978/09-1995/04 & 1995/05-2011/12 & Expansion & Recession \\
\hline \multirow{3}{*}{$\begin{array}{l}\text { 1. Long (Winner) } \\
\text { Short (Loser) }\end{array}$} & Return(bp) & 98.27 & 106.19 & 46.19 & 98.07 & 30.31 \\
\hline & T-value & (4.45) & $(4.76)$ & (1.17) & (5.53) & $(0.56)$ \\
\hline & Sharpe ratio & {$[0.266]$} & {$[0.348]$} & {$[0.090]$} & [0.259] & {$[0.054]$} \\
\hline \multirow{3}{*}{$\begin{array}{l}\text { 2. Long (Winner) } \\
\text { Short (Highly Convex in Loser) }\end{array}$} & Return(bp) & 103.83 & 98.11 & 42.84 & 94.08 & 33.50 \\
\hline & T-value & (4.39) & $(4.46)$ & $(1.03)$ & $(4.92)$ & $(0.61)$ \\
\hline & Sharpe ratio & {$[0.280]$} & {$[0.316]$} & {$[0.082]$} & {$[0.247]$} & {$[0.058]$} \\
\hline \multirow{3}{*}{$\begin{array}{l}\text { 3. Long (Winner) } \\
\text { Short (Highly Concave in Loser) }\end{array}$} & Return(bp) & 133.29 & 134.90 & 70.21 & 130.39 & 49.52 \\
\hline & T-value & (5.01) & (5.73) & $(1.80)$ & (7.69) & $(0.74)$ \\
\hline & Sharpe ratio & {$[0.342]$} & {$[0.420]$} & {$[0.121]$} & {$[0.318]$} & {$[0.078]$} \\
\hline \multirow{3}{*}{$\begin{array}{l}\text { 4. Long (Highly Concave in Winner) } \\
\text { Short (Loser) }\end{array}$} & Return(bp) & 65.75 & 82.59 & -0.50 & 59.57 & 15.66 \\
\hline & T-value & (3.11) & (3.57) & $(-0.01)$ & (3.07) & $(0.32)$ \\
\hline & Sharpe ratio & [0.173] & {$[0.258]$} & {$[-0.001]$} & [0.159] & {$[0.029]$} \\
\hline \multirow{3}{*}{$\begin{array}{l}\text { 5. Long (Highly Convex in Winner) } \\
\text { Short (Loser) }\end{array}$} & Return(bp) & 115.28 & 121.07 & 74.52 & 122.51 & 29.79 \\
\hline & T-value & $(4.60)$ & $(4.90)$ & $(1.70)$ & $(6.21)$ & $(0.48)$ \\
\hline & Sharpe ratio & [0.268] & [0.365] & [0.124] & [0.278] & {$[0.048]$} \\
\hline \multirow{3}{*}{$\begin{array}{l}\text { 6. Long (Highly Convex in Winner) } \\
\text { Short (Highly Concave in Loser) }\end{array}$} & Return(bp) & 150.30 & 149.78 & 98.53 & 154.83 & 49.00 \\
\hline & T-value & (5.04) & $(5.74)$ & $(2.22)$ & (7.99) & $(0.65)$ \\
\hline & Sharpe ratio & {$[0.340]$} & {$[0.430]$} & [0.145] & [0.324] & {$[0.071]$} \\
\hline \multirow{3}{*}{$\begin{array}{l}\text { 7. Long (Highly Concave in Winner) } \\
\text { Short (Highly Convex in Loser) }\end{array}$} & Return(bp) & 71.32 & 74.50 & -3.85 & 55.58 & 18.85 \\
\hline & T-value & (3.21) & (3.30) & $(-0.09)$ & (2.77) & $(0.40)$ \\
\hline & Sharpe ratio & [0.189] & {$[0.230]$} & {$[-0.008]$} & {$[0.146]$} & {$[0.034]$} \\
\hline \multirow{3}{*}{$\begin{array}{l}\text { 8. Long (Highly Convex in Winner) } \\
\text { Short (Highly Convex in Loser) }\end{array}$} & Return(bp) & 120.84 & 112.99 & 71.16 & 118.52 & 32.97 \\
\hline & T-value & $(4.82)$ & $(4.70)$ & $(1.60)$ & (5.92) & $(0.53)$ \\
\hline & Sharpe ratio & [0.287] & {$[0.341]$} & [0.122] & {$[0.277]$} & {$[0.053]$} \\
\hline \multirow{3}{*}{$\begin{array}{l}\text { 9. Long (Highly Concave in Winner) } \\
\text { Short (Highly Concave in Loser) }\end{array}$} & Return(bp) & 100.78 & 111.29 & 23.52 & 91.89 & 34.87 \\
\hline & T-value & $(4.23)$ & $(4.74)$ & $(0.63)$ & $(5.24)$ & $(0.60)$ \\
\hline & Sharpe ratio & {$[0.270]$} & {$[0.344]$} & {$[0.047]$} & {$[0.245]$} & {$[0.059]$} \\
\hline
\end{tabular}




\begin{tabular}{|c|c|c|c|c|c|c|}
\hline \multicolumn{7}{|c|}{ Panel B. Mean Comparison } \\
\hline Trading Strategy Comparison & & 196201-197808 & 1978/09-1995/04 & 1995/05-2011/12 & Expansion & Recession \\
\hline \multirow{2}{*}{$2-1$} & Return(bp) & 5.57 & -8.08 & -3.36 & -3.99 & 3.19 \\
\hline & T-value & $(0.73)$ & $(-1.05)$ & $(-0.25)$ & $(-0.53)$ & $(0.19)$ \\
\hline \multirow[t]{2}{*}{$3-1$} & Return(bp) & 35.02 & 28.70 & 24.01 & 32.32 & 19.21 \\
\hline & T-value & (3.35) & (3.84) & (1.67) & (5.09) & $(0.86)$ \\
\hline \multirow[t]{2}{*}{$4-1$} & Return(bp) & -32.51 & -23.61 & -46.69 & -38.50 & -14.65 \\
\hline & T-value & $(-3.26)$ & $(-3.90)$ & $(-3.63)$ & $(-5.80)$ & $(-0.79)$ \\
\hline \multirow[t]{2}{*}{$5-1$} & Return(bp) & 17.01 & 14.88 & 28.32 & 24.44 & -0.53 \\
\hline & T-value & $(1.81)$ & $(2.71)$ & $(2.24)$ & (3.73) & $(-0.03)$ \\
\hline \multirow[t]{2}{*}{$6-1$} & Return(bp) & 52.04 & 43.58 & 52.34 & 56.76 & 18.68 \\
\hline & T-value & (3.38) & (4.31) & (2.44) & (5.78) & $(0.57)$ \\
\hline \multirow[t]{2}{*}{$7-1$} & Return(bp) & -26.95 & -31.69 & -50.05 & -42.49 & -11.47 \\
\hline & T-value & $(-2.33)$ & $(-3.43)$ & $(-2.69)$ & $(-4.85)$ & $(-0.55)$ \\
\hline \multirow[t]{2}{*}{$8-1$} & Return(bp) & 22.58 & 6.79 & 24.97 & 20.45 & 2.66 \\
\hline & T-value & (2.59) & $(0.80)$ & (1.65) & (2.65) & $(0.12)$ \\
\hline \multirow[t]{2}{*}{$9-1$} & Return(bp) & 2.51 & 5.10 & -22.68 & -6.18 & 4.56 \\
\hline & T-value & $(0.24)$ & $(0.71)$ & $(-2.02)$ & $(-0.95)$ & $(0.25)$ \\
\hline \multirow[t]{2}{*}{$3-2$} & Return(bp) & 29.46 & 36.79 & 27.37 & 36.31 & 16.02 \\
\hline & T-value & (2.03) & (2.95) & (1.21) & (3.36) & $(0.54)$ \\
\hline \multirow[t]{2}{*}{$5-4$} & Return(bp) & 49.53 & 38.49 & 75.01 & 62.94 & 14.13 \\
\hline & T-value & (3.27) & $(4.46)$ & (3.54) & (5.96) & $(0.50)$ \\
\hline
\end{tabular}


Table 6 Performance of Trading Strategies Measured by Midpoints of Bid and Ask Quotes

This table presents the monthly profit in basis points, its $t$-value and the Sharpe ratio for nine trading strategies in Panel A. Panel B reports the t-values for the mean difference tests. All aspects of the strategy and calculations are identical to those in Table 2 except that we replace the daily closing prices by the midpoints of bid and ask quotes in return calculation. All common stocks listed in NYSE, AMEX, and Nasdaq ranging from January 1962 to December 2011 are included. However, stocks whose share prices are lower than a mid-quote of $\$ 5$ at the time of sorting and portfolio formation are deleted. All the panels are for a ranking period of 12 months lagged one month and hold periods of 6 months. The Sharpe ratio in brackets is defined as dividing the monthly portfolio excess return by the standard deviation of excess returns. For alphas, we divide alpha by the idiosyncratic volatility of the portfolio returns to be the Sharpe ratio. All the $t$-values in parentheses are adjusted for potential autocorrelation with the Newey-West procedure. Bolded $t$-values correspond to a significance level of $5 \%$ or higher. 


\begin{tabular}{|c|c|c|c|c|c|c|c|c|}
\hline \multicolumn{9}{|c|}{ Panel A. Portfolio Return } \\
\hline & \multirow[b]{2}{*}{ Trading Strategy } & & \multicolumn{3}{|c|}{ Raw Return } & \multicolumn{3}{|c|}{ Alphas from the Fama-FrenchThree-factor Model } \\
\hline & & & All Months & January Only & January Excluded & All Months & January Only & January Excluded \\
\hline \multirow[t]{3}{*}{1.} & Long (Winner) & Return(bp) & 92.96 & -67.73 & 107.66 & 114.03 & -66.10 & 134.06 \\
\hline & Short (Loser) & T-value & (3.43) & $(-1.06)$ & (3.73) & (5.05) & $(-1.00)$ & (5.69) \\
\hline & & Sharpe ratio & [0.204] & {$[-0.172]$} & [0.235] & [0.204] & {$[-0.172]$} & [0.235] \\
\hline \multirow{2}{*}{2.} & Short (Highly Convex in Loser) & T-value & (3.05) & $(-0.73)$ & (3.37) & $(4.20)$ & $(-0.93)$ & $(4.92)$ \\
\hline & & Sharpe ratio & {$[0.180]$} & {$[-0.134]$} & {$[0.207]$} & [0.180] & {$[-0.134]$} & {$[0.207]$} \\
\hline \multirow[t]{2}{*}{3.} & Long (Winner) & Return(bp) & 118.39 & -39.31 & 132.41 & 138.38 & -6.95 & 157.22 \\
\hline & Short (Highly Concave in Loser) & T-value & $(4.50)$ & $(-0.45)$ & (4.63) & (6.01) & $(-0.09)$ & $(6.22)$ \\
\hline \multirow{2}{*}{4.} & Short (Loser) & T-value & $(2.01)$ & $(-1.22)$ & $(2.32)$ & (3.41) & $(-1.00)$ & (4.12) \\
\hline & & Sharpe ratio & [0.132] & {$[-0.164]$} & {$[0.160]$} & [0.132] & {$[-0.164]$} & {$[0.160]$} \\
\hline \multirow[t]{3}{*}{5.} & Long (Highly Convex in Winner) & Return(bp) & 126.06 & -64.85 & 143.52 & 146.84 & -68.90 & 171.13 \\
\hline & Short (Loser) & T-value & (3.90) & $(-0.99)$ & (4.28) & (5.11) & $(-1.04)$ & (5.75) \\
\hline & & Sharpe ratio & [0.233] & {$[-0.133]$} & [0.265] & [0.233] & {$[-0.133]$} & [0.265] \\
\hline \multirow[t]{3}{*}{6.} & Long (Highly Convex in Winner) & Return(bp) & 144.43 & -69.34 & 163.43 & 165.03 & -33.75 & 190.06 \\
\hline & Short (Highly Concave in Loser) & T-value & $(4.83)$ & $(-0.68)$ & $(4.94)$ & $(5.85)$ & $(-0.40)$ & $(6.01)$ \\
\hline & & Sharpe ratio & [0.253] & {$[-0.091]$} & [0.298] & [0.253] & {$[-0.091]$} & [0.298] \\
\hline 8. & & Sharpe ratio & {$[0.214]$} & {$[-0.187]$} & {$[0.247]$} & {$[0.214]$} & {$[-0.187]$} & {$[0.247]$} \\
\hline \multirow[t]{3}{*}{9.} & Long (Highly Concave in Winner) & Return(bp) & 82.10 & -93.69 & 97.72 & 102.47 & -46.50 & 121.23 \\
\hline & Short (Highly Concave in Loser) & T-value & (3.11) & $(-1.15)$ & (3.52) & (4.64) & $(-0.64)$ & (5.21) \\
\hline & & Sharpe ratio & {$[0.180]$} & {$[-0.150]$} & [0.224] & {$[0.180]$} & {$[-0.150]$} & {$[0.224]$} \\
\hline
\end{tabular}




\begin{tabular}{|c|c|c|c|c|c|c|c|}
\hline \multicolumn{8}{|c|}{ Panel B. Mean Comparis on } \\
\hline \multirow[b]{2}{*}{ Trading Strategy Comparison } & & \multicolumn{3}{|c|}{ Raw Return } & \multicolumn{3}{|c|}{ Alphas from the Fama-FrenchThree-factor Model } \\
\hline & & All Months & January Only & January Excluded & All Months & January Only & January Excluded \\
\hline $2-1$ & T-value & $(-0.60)$ & $(0.20)$ & $(-0.72)$ & $(-1.05)$ & $(-0.26)$ & $(-1.19)$ \\
\hline \multirow[t]{2}{*}{$3-1$} & Return(bp) & 30.41 & 22.53 & 31.11 & 28.55 & 55.16 & 28.98 \\
\hline & T-value & (3.15) & $(0.42)$ & (2.19) & (3.37) & (1.46) & (2.69) \\
\hline $4-1$ & T-value & $(-3.22)$ & $(-0.16)$ & $(-3.40)$ & $(-3.69)$ & $(-0.14)$ & $(-4.11)$ \\
\hline \multirow[t]{2}{*}{$5-1$} & Return(bp) & 33.09 & 2.88 & 35.86 & 32.81 & -2.80 & 37.07 \\
\hline & T-value & (2.93) & $(0.06)$ & (3.29) & (3.02) & $(-0.09)$ & (3.46) \\
\hline \multirow[t]{2}{*}{$6-1$} & Return(bp) & 56.45 & -7.50 & 62.13 & 55.21 & 28.36 & 61.81 \\
\hline & T-value & (3.94) & $(-0.10)$ & (3.15) & (3.93) & $(0.50)$ & (3.49) \\
\hline $8-1$ & T-value & (1.98) & $(-1.01)$ & $(2.22)$ & (1.83) & $(-2.08)$ & (2.24) \\
\hline \multirow[t]{2}{*}{$9-1$} & Return(bp) & -5.88 & -31.85 & -3.57 & -7.35 & 15.60 & -7.01 \\
\hline & T-value & $(-0.69)$ & $(-0.59)$ & $(-0.37)$ & $(-0.83)$ & $(0.50)$ & $(-0.75)$ \\
\hline \multirow[t]{2}{*}{$3-2$} & Return(bp) & 35.97 & 17.45 & 37.61 & 36.81 & 61.30 & 38.35 \\
\hline & T-value & (2.42) & $(0.25)$ & (2.07) & (2.57) & (1.03) & $(2.32)$ \\
\hline \multirow[t]{2}{*}{$5-4$} & Return(bp) & 65.25 & 11.25 & 70.19 & 64.87 & 3.66 & 72.78 \\
\hline & T-value & (4.26) & $(0.26)$ & (3.96) & $(4.30)$ & $(0.08)$ & (4.23) \\
\hline
\end{tabular}




\section{Table 7 Performance of Trading Strategies in Different Exchanges}

This table presents results from repeating the analysis in Table 2 by partitioning the sample according to exchanges. All the panels are for a ranking period of 12 months lagged one month and hold periods of 6 months. Panel A shows the results for the common stocks listed in NYSE and AMEX and Panel B for stocks in Nasdaq. The sample period is from January, 1962 to December, 2010. At the time of sorting and portfolio formation, stocks with a share price of $\$ 5$ or lower are deleted. The Sharpe ratio in brackets is defined as dividing the monthly portfolio excess return by the standard deviation of excess returns. For alphas, we divide alpha by the idiosyncratic volatility of the portfolio returns to be the Sharpe ratio. All the $t$-values are corrected for autocorrelation with the Newey-West adjustment. Bolded $t$-values correspond to a significance level of $5 \%$ or higher. 


\begin{tabular}{|c|c|c|c|c|}
\hline \multicolumn{5}{|c|}{ Panel A. NYSE and AMEX } \\
\hline & & \multicolumn{3}{|c|}{ Raw Return } \\
\hline & & All months & January Only & January excluded \\
\hline 1. Long (Winner) & Return(bp) & 69.77 & -200.89 & 93.87 \\
\hline \multirow[t]{2}{*}{ Short (Loser) } & T-value & $(4.22)$ & $(-2.83)$ & (5.19) \\
\hline & Sharpe ratio & {$[0.181]$} & {$[-0.419]$} & {$[0.256]$} \\
\hline 2. Long (Winner) & Return(bp) & 67.72 & -162.08 & 88.19 \\
\hline \multirow[t]{2}{*}{ Short (Highly Convex in Loser) } & T-value & (4.12) & $(-2.38)$ & (5.15) \\
\hline & Sharpe ratio & {$[0.173]$} & {$[-0.371]$} & {$[0.232]$} \\
\hline 3. Long (Winner) & Return(bp) & 96.93 & -83.19 & 112.97 \\
\hline \multirow[t]{2}{*}{ Short (Highly Concave in Loser) } & T-value & (5.29) & $(-1.23)$ & $(5.60)$ \\
\hline & Sharpe ratio & {$[0.232]$} & {$[-0.149]$} & {$[0.283]$} \\
\hline \multirow{3}{*}{$\begin{array}{l}\text { 4. Long (Highly Concave in Winner) } \\
\text { Short (Loser) }\end{array}$} & Return(bp) & 44.29 & -228.58 & 68.59 \\
\hline & T-value & (2.71) & $(-2.63)$ & (3.78) \\
\hline & Sharpe ratio & {$[0.115]$} & {$[-0.449]$} & [0.188] \\
\hline \multirow{3}{*}{$\begin{array}{l}\text { 5. Long (Highly Convex in Winner) } \\
\text { Short (Loser) }\end{array}$} & Return(bp) & 87.27 & -263.45 & 118.51 \\
\hline & T-value & $(4.56)$ & $(-3.53)$ & $(5.72)$ \\
\hline & Sharpe ratio & [0.195] & {$[-0.458]$} & [0.281] \\
\hline \multirow{3}{*}{$\begin{array}{l}\text { 6. Long (Highly Convexin Winner) } \\
\text { Short (Highly Concave in Loser) }\end{array}$} & Return(bp) & 114.43 & -145.75 & 137.60 \\
\hline & T-value & (5.48) & $(-2.04)$ & (5.99) \\
\hline & Sharpe ratio & {$[0.239]$} & {$[-0.222]$} & {$[0.303]$} \\
\hline \multirow{3}{*}{$\begin{array}{l}\text { 7. Long (Highly Concave in Winner) } \\
\text { Short (Highly Convex in Loser) }\end{array}$} & Return(bp) & 42.25 & -189.77 & 62.91 \\
\hline & T-value & $(2.61)$ & $(-2.31)$ & (3.62) \\
\hline & Sharpe ratio & {$[0.107]$} & {$[-0.409]$} & {$[0.165]$} \\
\hline \multirow{3}{*}{$\begin{array}{l}\text { 8. Long (Highly Convex in Winner) } \\
\text { Short (Highly Convex in Loser) }\end{array}$} & Return(bp) & 85.23 & -224.64 & 112.82 \\
\hline & T-value & (4.59) & $(-3.23)$ & (5.83) \\
\hline & Sharpe ratio & [0.192] & {$[-0.424]$} & {$[0.265]$} \\
\hline \multirow{3}{*}{$\begin{array}{l}\text { 9. Long (Highly Concave in Winner) } \\
\text { Short (Highly Concave in Loser) }\end{array}$} & Return(bp) & 71.45 & -110.88 & 87.69 \\
\hline & T-value & $(4.07)$ & $(-1.48)$ & $(4.52)$ \\
\hline & Sharpe ratio & [0.179] & {$[-0.203]$} & {$[0.231]$} \\
\hline \multicolumn{5}{|c|}{ Mean Comparison } \\
\hline Trading Strategy Comparison & & All Months & January Only & January Excluded \\
\hline \multirow[t]{2}{*}{$2-1$} & Return(bp) & -2.04 & 38.82 & -5.68 \\
\hline & T-value & $(-0.38)$ & $(1.91)$ & $(-0.99)$ \\
\hline \multirow[t]{2}{*}{$3-1$} & Return(bp) & 27.16 & 117.71 & 19.10 \\
\hline & T-value & (4.85) & (3.72) & (3.09) \\
\hline \multirow[t]{2}{*}{$4-1$} & Return(bp) & -25.47 & -27.69 & -25.28 \\
\hline & T-value & $(-4.68)$ & $(-0.89)$ & $(-3.87)$ \\
\hline \multirow[t]{2}{*}{$5-1$} & Return(bp) & 17.51 & -62.56 & 24.64 \\
\hline & T-value & (3.21) & $(-2.73)$ & (4.55) \\
\hline \multirow[t]{2}{*}{$6-1$} & Return(bp) & 44.67 & 55.15 & 43.73 \\
\hline & T-value & (5.38) & (1.43) & (4.71) \\
\hline \multirow[t]{2}{*}{$7-1$} & Return(bp) & -27.52 & 11.13 & -30.96 \\
\hline & T-value & $(-3.60)$ & (0.36) & $(-3.44)$ \\
\hline $8-1$ & Return(bp) & 15.46 & -23.74 & 18.95 \\
\hline & T-value & $(2.42)$ & $(-0.98)$ & (3.00) \\
\hline $9-1$ & Return(bp) & 1.69 & 90.02 & -6.18 \\
\hline & T-value & $(0.27)$ & (4.17) & $(-0.88)$ \\
\hline $3-2$ & Return(bp) & 29.20 & 78.89 & 24.78 \\
\hline & T-value & (3.35) & (2.86) & (2.53) \\
\hline $5-4$ & Return(bp) & 42.98 & -34.87 & 49.91 \\
\hline & T-value & (5.15) & $(-0.84)$ & (5.11) \\
\hline
\end{tabular}




\begin{tabular}{|c|c|c|c|c|}
\hline \multicolumn{5}{|c|}{ Panel B. Nasdaq } \\
\hline & & \multicolumn{3}{|c|}{ Raw Return } \\
\hline & & All months & January Only & January excluded \\
\hline 1. Long (Winner) & Return(bp) & 94.62 & -111.03 & 112.82 \\
\hline \multirow[t]{2}{*}{ Short (Loser) } & T-value & $(4.35)$ & $(-1.70)$ & $(4.92)$ \\
\hline & Sharpe ratio & {$[0.222]$} & {$[-0.242]$} & {$[0.269]$} \\
\hline 2. Long (Winner) & Return(bp) & 84.49 & -113.14 & 101.99 \\
\hline \multirow[t]{2}{*}{ Short (Highly Convex in Loser) } & T-value & (3.57) & $(-1.33)$ & $(4.13)$ \\
\hline & Sharpe ratio & {$[0.192]$} & {$[-0.220]$} & {$[0.237]$} \\
\hline 3. Long (Winner) & Return(bp) & 126.56 & -60.39 & 143.11 \\
\hline \multirow[t]{2}{*}{ Short (Highly Concave in Loser) } & T-value & (5.95) & $(-0.74)$ & (6.26) \\
\hline & Sharpe ratio & {$[0.272]$} & {$[-0.094]$} & [0.323] \\
\hline \multirow{3}{*}{$\begin{array}{l}\text { 4. Long (Highly Concave in Winner) } \\
\text { Short (Loser) }\end{array}$} & Return(bp) & 56.01 & -197.97 & 78.50 \\
\hline & T-value & $(2.41)$ & $(-3.16)$ & (3.17) \\
\hline & Sharpe ratio & {$[0.130]$} & {$[-0.433]$} & [0.187] \\
\hline \multirow{3}{*}{$\begin{array}{l}\text { 5. Long (Highly Convex in Winner) } \\
\text { Short (Loser) }\end{array}$} & Return(bp) & 120.26 & -149.39 & 144.13 \\
\hline & T-value & $(4.85)$ & $(-2.23)$ & (5.46) \\
\hline & Sharpe ratio & [0.245] & {$[-0.290]$} & [0.299] \\
\hline \multirow{3}{*}{$\begin{array}{l}\text { 6. Long (Highly Convexin Winner) } \\
\text { Short (Highly Concave in Loser) }\end{array}$} & Return(bp) & 152.21 & -98.75 & 174.42 \\
\hline & T-value & (6.16) & $(-1.15)$ & (6.47) \\
\hline & Sharpe ratio & {$[0.288]$} & {$[-0.136]$} & {$[0.348]$} \\
\hline \multirow{3}{*}{$\begin{array}{l}\text { 7. Long (Highly Concave in Winner) } \\
\text { Short (Highly Convex in Loser) }\end{array}$} & Return(bp) & 45.89 & -200.08 & 67.66 \\
\hline & T-value & (1.85) & $(-2.38)$ & (2.58) \\
\hline & Sharpe ratio & {$[0.104]$} & {$[-0.396]$} & {$[0.157]$} \\
\hline \multirow{3}{*}{$\begin{array}{l}\text { 8. Long (Highly Convex in Winner) } \\
\text { Short (Highly Convex in Loser) }\end{array}$} & Return(bp) & 110.14 & -151.50 & 133.30 \\
\hline & T-value & (4.28) & $(-1.82)$ & $(4.90)$ \\
\hline & Sharpe ratio & {$[0.226]$} & {$[-0.274]$} & {$[0.280]$} \\
\hline \multirow{3}{*}{$\begin{array}{l}\text { 9. Long (Highly Concave in Winner) } \\
\text { Short (Highly Concave in Loser) }\end{array}$} & Return(bp) & 87.96 & -147.33 & 108.79 \\
\hline & T-value & $(4.14)$ & $(-1.83)$ & $(4.96)$ \\
\hline & Sharpe ratio & {$[0.200]$} & {$[-0.227]$} & {$[0.265]$} \\
\hline \multicolumn{5}{|c|}{ Mean Comparison } \\
\hline Trading Strategy Comparison & & All Months & January Only & January Excluded \\
\hline \multirow[t]{2}{*}{$2-1$} & Return(bp) & -10.12 & -2.11 & -10.83 \\
\hline & T-value & $(-1.22)$ & $(-0.07)$ & $(-1.29)$ \\
\hline \multirow[t]{2}{*}{$3-1$} & Return(bp) & 31.95 & 50.64 & 30.29 \\
\hline & T-value & (3.59) & $(0.91)$ & (2.34) \\
\hline \multirow[t]{2}{*}{$4-1$} & Return(bp) & -38.60 & -86.95 & -34.32 \\
\hline & T-value & $(-4.94)$ & $(-3.78)$ & $(-4.32)$ \\
\hline \multirow[t]{2}{*}{$5-1$} & Return(bp) & 25.65 & -38.36 & 31.31 \\
\hline & T-value & (3.07) & $(-1.60)$ & (3.52) \\
\hline \multirow[t]{2}{*}{$6-1$} & Return(bp) & 57.59 & 12.28 & 61.61 \\
\hline & T-value & (4.47) & $(0.19)$ & (3.68) \\
\hline \multirow[t]{2}{*}{$7-1$} & Return(bp) & -48.72 & -89.05 & -45.15 \\
\hline & T-value & $(-4.51)$ & $(-2.12)$ & $(-4.00)$ \\
\hline $8-1$ & Return(bp) & 15.52 & -40.47 & 20.48 \\
\hline & T-value & (1.57) & $(-1.20)$ & (1.94) \\
\hline $9-1$ & Return(bp) & -6.65 & -36.30 & -4.03 \\
\hline & T-value & $(-0.79)$ & $(-0.58)$ & $(-0.40)$ \\
\hline $3-2$ & Return(bp) & 42.07 & 52.75 & 41.12 \\
\hline & T-value & (3.18) & $(0.67)$ & (2.50) \\
\hline $5-4$ & Return(bp) & 64.25 & 48.58 & 65.64 \\
\hline & T-value & (4.87) & (1.29) & (4.74) \\
\hline
\end{tabular}




\section{Table 8 Performance of Trading Strategies under Longer Holding Periods}

This table shows the profit, its $t$-value and the Sharpe ratio for nine trading strategies with longer holding periods. All common stocks listed in NYSE, AMEX , and Nasdaq from January, 1962 to December, 2010 are included. At the time of sorting and portfolio formation, we filter out the stocks whose share price are lower than \$5. The sorting and portfolio construction procedures are identical to Table 2. All the panels are for a ranking period of 12 months lagged one month. The only difference is with respect to the holding period. Unlike the 6-month holding period in Table 2, we hold the nine strategies for 1, 12, 24, 36, 48, and 60 months respectively. The reported profits (in basis points) are average monthly returns of the overlapping portfolios. All $t$-values are corrected for potential autocorrelation with the Newey-West adjustment. Bolded $t$-values correspond to a significance level of $5 \%$ or higher.

\begin{tabular}{|c|c|c|c|c|c|c|c|}
\hline \multicolumn{8}{|c|}{ Panel A. Raw Return } \\
\hline & $\mathrm{K}=$ & 1 month & 12 months & 24 months & 36 months & 48 months & 60 months \\
\hline 1. Long (Winner) & Return(bp) & 121.36 & 45.15 & 13.59 & 3.65 & 0.24 & -3.70 \\
\hline \multirow[t]{2}{*}{ Short (Loser) } & T-value & (6.14) & (3.01) & $(1.27)$ & $(0.41)$ & $(0.03)$ & $(-0.58)$ \\
\hline & Sharpe ratio & {$[0.260]$} & {$[0.131]$} & [0.055] & [0.019] & {$[0.002]$} & {$[-0.027]$} \\
\hline 2. Long (Winner) & Return(bp) & 141.12 & 39.24 & 9.44 & 2.38 & 2.22 & -2.38 \\
\hline \multirow[t]{2}{*}{ Short (Highly Convex in Loser) } & T-value & $(6.65)$ & (2.55) & $(0.85)$ & $(0.26)$ & $(0.31)$ & $(-0.37)$ \\
\hline & Sharpe ratio & {$[0.287]$} & {$[0.113]$} & {$[0.038]$} & [0.012] & {$[0.014]$} & {$[-0.017]$} \\
\hline 3. Long (Winner) & Return(bp) & 132.78 & 73.91 & 30.88 & 16.79 & 9.72 & 4.52 \\
\hline \multirow[t]{2}{*}{ Short (Highly Concave in Loser) } & T-value & $(6.52)$ & $(4.82)$ & (2.78) & $(1.84)$ & $(1.31)$ & $(0.69)$ \\
\hline & Sharpe ratio & {$[0.248]$} & [0.207] & [0.122] & {$[0.088]$} & {$[0.062]$} & [0.033] \\
\hline 4 Long (Highly Concave in Winner) & Return(bp) & 86.10 & 19.94 & -3.43 & -7.34 & -8.75 & -11.45 \\
\hline \multirow[t]{2}{*}{ Short (Loser) } & T-value & (3.95) & $(1.34)$ & $(-0.30)$ & $(-0.76)$ & $(-1.09)$ & $(-1.54)$ \\
\hline & Sharpe ratio & {$[0.192]$} & [0.059] & {$[-0.013]$} & {$[-0.036]$} & {$[-0.050]$} & {$[-0.072]$} \\
\hline 5. Long (Highly Convex in Winner) & Return(bp) & 132.59 & 57.45 & 16.95 & 3.55 & 0.88 & -3.88 \\
\hline \multirow[t]{2}{*}{ Short (Loser) } & T-value & $(6.02)$ & (3.39) & $(1.38)$ & $(0.34)$ & $(0.09)$ & $(-0.43)$ \\
\hline & Sharpe ratio & {$[0.246]$} & {$[0.144]$} & {$[0.057]$} & {$[0.015]$} & {$[0.004]$} & {$[-0.022]$} \\
\hline 6. Long (Highly Convex in Winner) & Return(bp) & 144.01 & 86.21 & 34.24 & 16.70 & 10.36 & 4.35 \\
\hline \multirow[t]{2}{*}{ Short (Highly Concave in Loser) } & T-value & $(6.18)$ & $(5.01)$ & $(2.81)$ & $(1.65)$ & $(1.17)$ & $(0.52)$ \\
\hline & Sharpe ratio & {$[0.236]$} & [0.211] & {$[0.116]$} & {$[0.075]$} & {$[0.055]$} & {$[0.026]$} \\
\hline 7. Long (Highly Concave in Winner) & Return(bp) & 105.86 & 14.04 & -7.58 & -8.60 & -6.77 & -10.12 \\
\hline \multirow[t]{2}{*}{ Short (Highly Convex in Loser) } & T-value & $(4.60)$ & $(0.93)$ & $(-0.67)$ & $(-0.94)$ & $(-0.95)$ & $(-1.59)$ \\
\hline & Sharpe ratio & {$[0.219]$} & [0.042] & {$[-0.030]$} & {$[-0.044]$} & {$[-0.042]$} & {$[-0.071]$} \\
\hline 8 Long (Highly Convex in Winner) & Return(bp) & 152.34 & 51.54 & 12.80 & 2.29 & 2.86 & -2.56 \\
\hline \multirow[t]{2}{*}{ Short (Highly Convex in Loser) } & T-value & $(6.70)$ & (3.13) & $(1.11)$ & $(0.24)$ & $(0.36)$ & $(-0.34)$ \\
\hline & Sharpe ratio & {$[0.280]$} & [0.133] & {$[0.045]$} & {$[0.011]$} & {$[0.016]$} & {$[-0.016]$} \\
\hline 9. Long (Highly Concave in Winner) & Return(bp) & 97.52 & 48.70 & 13.86 & 5.81 & 0.73 & -3.22 \\
\hline \multirow[t]{2}{*}{ Short (Highly Concave in Loser) } & T-value & (4.73) & (3.35) & $(1.24)$ & $(0.63)$ & $(0.10)$ & $(-0.46)$ \\
\hline & Sharpe ratio & {$[0.205]$} & {$[0.145]$} & {$[0.055]$} & {$[0.030]$} & {$[0.004]$} & {$[-0.022]$} \\
\hline
\end{tabular}




\begin{tabular}{|c|c|c|c|c|c|c|c|}
\hline \multicolumn{8}{|c|}{ Panel B. Mean Comparison } \\
\hline Trading Strategy Comparison & & 1 month & 12 months & 24 months & 36 months & 48 months & 60 months \\
\hline \multirow[t]{2}{*}{$2-1$} & Return(bp) & 19.75 & -5.91 & -4.15 & -1.27 & 1.98 & 1.33 \\
\hline & T-value & (2.74) & $(-1.13)$ & $(-0.90)$ & $(-0.30)$ & $(0.50)$ & $(0.36)$ \\
\hline \multirow[t]{2}{*}{ 3-1 } & Return(bp) & 11.42 & 28.76 & 17.29 & 13.15 & 9.48 & 8.23 \\
\hline & T-value & (1.34) & (7.48) & (5.66) & (4.89) & (3.58) & (3.49) \\
\hline \multirow[t]{2}{*}{$4-1$} & Return(bp) & -35.26 & -25.20 & -17.02 & -10.98 & -8.99 & -7.74 \\
\hline & T-value & $(-4.50)$ & $(-5.82)$ & $(-4.61)$ & $(-3.60)$ & $(-3.13)$ & $(-2.58)$ \\
\hline \multirow[t]{2}{*}{$5-1$} & Return(bp) & 11.23 & 12.30 & 3.36 & -0.09 & 0.64 & -0.18 \\
\hline & T-value & (1.43) & (2.46) & $(0.75)$ & $(-0.02)$ & $(0.16)$ & $(-0.04)$ \\
\hline \multirow[t]{2}{*}{ 6-1 } & Return(bp) & 22.64 & 41.06 & 20.65 & 13.05 & 10.12 & 8.05 \\
\hline & T-value & (1.74) & (6.58) & (4.87) & (3.76) & (3.38) & (2.67) \\
\hline \multirow[t]{2}{*}{$7-1$} & Return(bp) & -15.51 & -31.11 & -21.18 & -12.25 & -7.01 & -6.42 \\
\hline & T-value & $(-1.50)$ & $(-4.90)$ & $(-4.47)$ & $(-3.38)$ & $(-2.25)$ & $(-2.21)$ \\
\hline \multirow[t]{2}{*}{ 8-1 } & Return(bp) & 30.98 & 6.40 & -0.80 & -1.36 & 2.61 & 1.15 \\
\hline & T-value & (3.34) & $(1.32)$ & $(-0.21)$ & $(-0.45)$ & (0.99) & $(0.46)$ \\
\hline \multirow[t]{2}{*}{$9-1$} & Return(bp) & -23.84 & 3.56 & 0.26 & 2.16 & 0.49 & 0.48 \\
\hline & T-value & $(-3.07)$ & $(0.92)$ & $(0.09)$ & $(0.98)$ & $(0.22)$ & $(0.21)$ \\
\hline \multirow[t]{2}{*}{ 3-2 } & Return(bp) & -8.34 & 34.67 & 21.44 & 14.41 & 7.50 & 6.90 \\
\hline & T-value & $(-0.67)$ & (5.73) & (5.51) & (4.53) & (2.55) & (2.57) \\
\hline \multirow[t]{2}{*}{$5-4$} & Return(bp) & 46.49 & 37.51 & 20.38 & 10.89 & 9.63 & 7.57 \\
\hline & T-value & (3.62) & (5.57) & (4.32) & (3.02) & (3.20) & (2.42) \\
\hline
\end{tabular}




\section{Appendix 1 Performance of Trading Strategies Estimated by Simple Raw Returns and Risk-Adjusted Returns: Alternative ranking and holding periods}

This table reports the average monthly returns, the $t$-values, and the Sharpe ratios for nine trading strategies from January 1962 to December 2011. The sample includes all common stocks listed in NYSE, AMEX, and Nasdaq. At the time of sorting and portfolio formation, stocks with a share price of $\$ 5$ or lower are deleted. For brevity, stocks are sorted to quintiles based on the past 24-month returns lagged one month. All equally-weighted portfolios are held for 6 month. The convexity and concavity for each stock are defined by regressing the daily prices in the past 12 months on the variable $t$ and the square of $t$ for each stock, where $t$ is an arithmetic sequence, which is equal to $1,2,3 \ldots$ or $n$ for the indication of the past $n, \ldots, 3,2$, or 1 day respectively. Stocks whose coefficients of the square of $t$ are the top 20\% are those with highly convex-shaped past prices; conversely, stocks whose coefficients of the square of $t$ are the bottom 20\% are those with highly concave-shaped past prices. The nine trading strategies are constructed by buying and selling the stocks with different visual patterns of past prices. Panel A presents the returns in basis points, the $t$-values, and the Sharpe ratios of the nine trading strategies. The Sharpe ratio in brackets is defined as dividing the excess return of a portfolio by the standard deviation of this excess return. For alphas, the Sharpe ratio is actually the appraisal ratio: Alpha divided by the idiosyncratic volatility of the portfolio returns. The $t$-statistics in parentheses are adjusted for autocorrelation using the Newey-West covariance matrix. For Panel B, the $t$-statistics in parentheses examine whether the performance difference between two different portfolios is significantly different from zero, and Bolded $t$-values correspond to a significance level of $5 \%$ or higher. 


\begin{tabular}{|c|c|c|c|c|c|c|c|}
\hline \multicolumn{8}{|c|}{ Panel A. Portfolio Return } \\
\hline & & \multicolumn{3}{|c|}{ Raw Return } & \multicolumn{3}{|c|}{ Alphas from the Fama-FrenchThree-factor Model } \\
\hline Trading Strategy & & All Months & January Only & January Excluded & All Months & January Only & January Excluded \\
\hline \multirow{2}{*}{ 1. Long (Winner) } & T-value & $(2.22)$ & $(-3.32)$ & (3.69) & $(5.24)$ & $(-1.44)$ & (6.57) \\
\hline & Sharpe ratio & [0.095] & {$[-0.600]$} & [0.185] & [0.095] & {$[-0.600]$} & [0.185] \\
\hline \multirow{2}{*}{$\begin{array}{l}\text { 2. Long (Winner) } \\
\text { Short (Highly Convex in Loser) }\end{array}$} & T-value & $(0.84)$ & $(-3.64)$ & $(2.24)$ & (2.67) & $(-1.43)$ & (3.54) \\
\hline & Sharpe ratio & [0.037] & [-0.599] & [0.109] & {$[0.037]$} & {$[-0.599]$} & [0.109] \\
\hline \multirow{2}{*}{$\begin{array}{l}\text { 3. Long (Winner) } \\
\text { Short (Highly Concave in Loser) }\end{array}$} & Return(bp) & 83.05 & -188.02 & 107.18 & 121.95 & -24.55 & 136.25 \\
\hline & T-value & $(4.17)$ & $(-2.28)$ & (5.01) & (7.03) & $(-0.26)$ & (7.83) \\
\hline \multirow{2}{*}{$\begin{array}{l}\text { 4. Long (Highly Concave in Winner) } \\
\text { Short (Loser) }\end{array}$} & T-value & (0.08) & $(-3.71)$ & (1.88) & (2.39) & $(-1.83)$ & (3.50) \\
\hline & Sharpe ratio & [0.004] & {$[-0.678]$} & [0.097] & [0.004] & {$[-0.678]$} & [0.097] \\
\hline \multirow{3}{*}{$\begin{array}{l}\text { 5. Long (Highly Convex in Winner) } \\
\text { Short (Loser) }\end{array}$} & Return(bp) & 64.44 & -337.52 & 100.22 & 119.56 & -122.27 & 141.61 \\
\hline & T-value & (3.26) & $(-3.63)$ & (4.64) & (7.44) & $(-1.61)$ & (8.70) \\
\hline & Sharpe ratio & [0.138] & [-0.599] & [0.228] & [0.138] & {$[-0.599]$} & [0.228] \\
\hline \multirow{2}{*}{$\begin{array}{l}\text { 6. Long (Highly Convex in Winner) } \\
\text { Short (Highly Concave in Loser) }\end{array}$} & Return(bp) & 111.63 & -235.25 & 142.51 & 168.12 & -33.04 & 186.62 \\
\hline & T-value & (4.65) & $(-2.76)$ & (5.50) & (8.16) & $(-0.36)$ & (8.86) \\
\hline \multirow{2}{*}{$\begin{array}{l}\text { 8. Long (Highly Convex in Winner) } \\
\text { Short (Highly Convex in Loser) }\end{array}$} & T-value & (2.34) & $(-3.97)$ & (3.87) & (5.62) & $(-1.56)$ & (6.77) \\
\hline & Sharpe ratio & [0.094] & {$[-0.605]$} & [0.175] & [0.094] & {$[-0.605]$} & [0.175] \\
\hline \multirow{3}{*}{$\begin{array}{l}\text { 9. Long (Highly Concave in Winner) } \\
\text { Short (Highly Concave in Loser) }\end{array}$} & Return(bp) & 48.62 & -267.56 & 76.76 & 85.58 & -60.09 & 99.47 \\
\hline & T-value & (2.64) & $(-3.01)$ & (3.85) & (5.17) & $(-0.60)$ & (5.99) \\
\hline & Sharpe ratio & [0.120] & {$[-0.523]$} & {$[0.200]$} & {$[0.120]$} & {$[-0.523]$} & [0.200] \\
\hline
\end{tabular}




\begin{tabular}{|c|c|c|c|c|c|c|c|}
\hline \multicolumn{8}{|c|}{ Panel B. Mean Comparison } \\
\hline \multirow[b]{2}{*}{ Trading Strategy Comparison } & & \multicolumn{3}{|c|}{ Raw Return } & \multicolumn{3}{|c|}{ Alphas from the Fama-FrenchThree-factor Model } \\
\hline & & All Months & January Only & January Excluded & All Months & January Only & January Excluded \\
\hline $2-1$ & T-value & $(-2.69)$ & $(0.37)$ & $(-2.96)$ & $(-3.20)$ & $(-0.08)$ & $(-3.25)$ \\
\hline \multirow[t]{2}{*}{$3-1$} & Return(bp) & 47.21 & 102.26 & 42.31 & 47.78 & 53.77 & 45.86 \\
\hline & T-value & (5.67) & (2.66) & (4.97) & (6.36) & (1.56) & (5.89) \\
\hline $4-1$ & T-value & $(-4.05)$ & $(-2.75)$ & $(-3.42)$ & $(-3.73)$ & $(-1.40)$ & $(-3.52)$ \\
\hline \multirow[t]{2}{*}{$5-1$} & Return(bp) & 28.60 & -47.23 & 35.35 & 34.29 & -15.87 & 38.93 \\
\hline & T-value & (3.16) & $(-1.84)$ & (3.84) & (3.49) & $(-0.53)$ & $(4.02)$ \\
\hline \multirow[t]{2}{*}{$6-1$} & Return(bp) & 75.82 & 55.03 & 77.67 & 82.07 & 37.90 & 84.79 \\
\hline & T-value & (5.33) & (1.39) & (5.31) & (5.64) & $(0.76)$ & (5.78) \\
\hline $8-1$ & T-value & (0.89) & $(-0.98)$ & (1.47) & (1.04) & $(-0.42)$ & (1.53) \\
\hline \multirow[t]{2}{*}{$9-1$} & Return(bp) & 12.76 & 22.72 & 11.88 & 18.07 & 25.23 & 15.72 \\
\hline & T-value & (1.67) & (0.69) & (1.46) & (2.28) & (0.65) & (1.90) \\
\hline \multirow[t]{2}{*}{$3-2$} & Return(bp) & 68.83 & 91.46 & 66.82 & 72.91 & 56.14 & 72.35 \\
\hline & T-value & (5.10) & (2.09) & (4.73) & (5.59) & (1.13) & (5.32) \\
\hline \multirow[t]{2}{*}{$5-4$} & Return(bp) & 63.05 & 32.31 & 65.79 & 64.01 & 12.67 & 69.06 \\
\hline & T-value & (4.17) & (0.83) & (4.15) & (3.97) & $(0.30)$ & (4.14) \\
\hline
\end{tabular}

